\title{
¿EL RetrocesO de LOS DERECHOS HUMANOS EN EUROPA?
}

\section{Laurence R. Helfer}

Duke University School of Law

helfer@law.duke.edu

\section{Erik Voeten}

Georgetown University

ev42@georgetown.edu

Recibido: 28/05/2021

Aceptado: $11 / 10 / 2021$

\section{Resumen}

Jueces y académicos llevan mucho tiempo debatiendo si el Tribunal Europeo de Derechos Humanos (en adelante, TEDH o el Tribunal) puede solo ampliar la protección de los derechos humanos en Europa, pero nunca disminuirlos. Estudios recientes han constatado que las reacciones políticas y las restricciones nacionales han influido en la jurisprudencia del TEDH. Sin embargo, analizar si el TEDH está cambiando hacia una dirección regresiva supone un reto empírico: ¿cómo podemos determinar si el Tribunal está limitando los derechos a lo largo del tiempo si nunca ha revocado expresamente una sentencia anterior en un sentido que favorezca al Gobierno? Para responder a esta pregunta, analizamos todas las opiniones separadas y minoritarias de la Gran Sala del TEDH entre 1998 y 2018. Nos centramos en las opiniones que afirman que la Gran Sala ha revocado tácitamente sentencias anteriores o doctrina establecida para favorecer al Estado demandado, lo que denominamos “disidencias por regresión”. Descubrimos que estas se han vuelto significativamente más comunes en la última década, lo que revela que algunos miembros del TEDH creen que la Gran Sala está revocando cada vez más sentencias anteriores en una dirección regresiva.

Palabras clave: derechos humanos, Tribunal Europeo de Derechos Humanos, disidencias por regresión, derechos protegidos, revocación de sentencias anteriores, democracias establecidas, doctrinas jurídicas anteriores. 


\title{
Walking Back Human Rights in Europe?
}

\begin{abstract}
Judges and scholars have long debated whether the European Court of Human Rights (the ECtHR or the Court) can only expand, never diminish, human rights protections in Europe. Recent studies have found that political backlashes and national-level restrictions have influenced ECtHR case law. However, analysing whether the ECtHR is shifting in a regressive direction faces an empirical challenge: How can we observe whether the Court is limiting rights over time if it has never expressly overturned a prior judgment in a way that favours the government? We gain traction on this question by analysing all separate and minority opinions of the ECtHR Grand Chamber between 1998 and 2018. We focus on opinions as- serting that the Grand Chamber has tacitly overturned prior rulings or settled doctrine in a way that favours the respondent state, which we label as 'walking back dissents'. We find that walking back dissents have become significantly more common in the last decade, revealing that some members of the ECtHR themselves believe that the Grand Chamber is increasingly overturning prior judgments in a regressive direction.
\end{abstract}

Key words: human rights, European Court of Human Rights, walking back dissents, protected rights, overturn prior judgments, established democracies, prior legal doctrines.

\section{Introducción ${ }^{1}$}

Los derechos humanos en Europa son un continuo trabajo en curso. Las libertades individuales protegidas por el Convenio Europeo de Derechos Humanos no están fijadas ni en el texto del tratado ni en la intención de sus redactores. En cambio, el Convenio es reinterpretado sistemáticamente por los 47 jueces del Tribunal Europeo de Derechos Humanos. Aplicando un enfoque interpretativo famoso por su dinamismo y evolución, el Tribunal ha considerado que leyes y prácticas nacionales que anteriormente no planteaban problemas de derechos humanos contravenían el Convenio cuando se reevaluaban con posterioridad a la luz de las tendencias regionales progresistas en materia de legislación, política y opinión pública. Quizás, lo más sorprendente sea que el TEDH no ha dudado en anular explícitamente sus sentencias anteriores para ampliar los derechos protegidos.

1 Agradecemos a los participantes de la Conferencia iCourts 2.0 de la Universidad de Copenhague, el taller Paths of International Law del Graduate Institute of International and Development Studies de Ginebra y el taller de la facultad de Derecho de Duke por sus valiosos comentarios y sugerencias. Emmie Bultemeier y Lauren Hughes han prestado una excelente ayuda en la codificación de los casos. Esta es una traducción al español de: Helfer, L. R. y Voeten, E. (2020). Walking Back Human Rights in Europe? European Journal of International Law, 31(3), 797-827. https://doi.org/10.1093/ejil/chaa071. 
Pero ¿qué sucede si las tendencias europeas se mueven en la otra dirección? Si los Estados reducen la protección de ciertas libertades individuales -en respuesta a la preocupación por el terrorismo o la migración, por ejemplo-, ¿debería el TEDH revisar su jurisprudencia anterior y restringir los derechos humanos en Europa? Como se explica en el apartado 3, los académicos han debatido durante mucho tiempo si el Tribunal puede solo ampliar, y nunca disminuir, los derechos humanos. Durante muchos años, estos desacuerdos nunca se pusieron a prueba en la práctica; las protecciones de los derechos humanos a nivel nacional -y la jurisprudencia del Tribunal que las refleja- se movieron en una sola dirección.

Sin embargo, a partir de mediados de la década de 2000, funcionarios del Ejecutivo, legisladores y jueces de varios países empezaron a criticar al TEDH por llevar la protección de los derechos humanos demasiado lejos. En una serie de temas de gran repercusión y políticamente sensibles -como los derechos de los acusados de delitos, los sospechosos de terrorismo, los solicitantes de asilo y las familias no tradicionales-, el Tribunal interpretó de forma expansiva el Convenio Europeo de Derechos Humanos (en adelante, CEDH o el Convenio $)^{2}$ y limitó la discrecionalidad jurídica y política de los Gobiernos. El descontento con el TEDH pronto pasó de reclamos públicos a acciones concretas: - En la Declaración de Brighton de $2012^{3}$ y en posteriores declaraciones y enmiendas al Convenio, los Estados señalaron de manera colectiva que el TEDH debía concederles una mayor deferencia. ${ }^{4}$

- Varios Estados han reducido las protecciones legales internas, especialmente en el ámbito de la inmigración. ${ }^{5}$

- Algunas democracias consolidadas, que tradicionalmente han apoyado al TEDH, se han negado a ejecutar las sentencias ${ }^{6}$ o las han impugnado abiertamente. ${ }^{7}$

- Algunos políticos y partidos adoptaron posturas escépticas respecto a los derechos humanos internacionales e incluso manifestaron su interés por abandonar el CEDH (Ciacchi, 2017).

2 Convenio Europeo para la Protección de los Derechos Humanos y de las Libertades Fundamentales (CEDH), 4 de noviembre de 1950, 213 UNTS 221, modificado.

3 Conferencia de alto nivel sobre el futuro del Tribunal Europeo de Derechos Humanos, Declaración de Brighton (20 de abril de 2012).

4 Véase, por ejemplo, Comisión Directiva del Consejo de Europa para los Derechos Humanos (2015).

5 Véase, por ejemplo, Kennedy (2019).

6 Véase, por ejemplo, Bates (2015).

7 Véase, por ejemplo, McGoldrick (2011). 
Cuando los Estados cambian colectivamente en una dirección progresista, el TEDH se basa en esas tendencias para revocar explícitamente sus sentencias anteriores y emitir decisiones que "impulsan" a los países rezagados, llevándolos a adoptar reformas más rápidamente, un patrón que hemos documentado en el caso de los derechos LGBT (Helfer y Voeten, 2014, pp. 95-96). ${ }^{8}$ Pero ¿qué ocurre cuando los países se mueven, por término medio, en una dirección regresiva y los Gobiernos se oponen públicamente a ampliar el alcance de la Convención? Si el TEDH se aferra a su enfoque expansionista, corre el riesgo de provocar una reacción que podría reducir su influencia. Como alternativa, podría ajustar su jurisprudencia para seguir las tendencias nacionales restrictivas de los derechos. ${ }^{9}$ Pero este enfoque también implica riesgos. Puede alienar a los grupos que apoyan al Tribunal y limitar la protección de los derechos de aquellos individuos y grupos desfavorecidos que el Tribunal ha identificado que necesitan especialmente su ayuda.

Cualquier análisis sobre si la jurisprudencia del TEDH está cambiando hacia una dirección restrictiva de los derechos se enfrenta a un reto empírico: ¿cómo podemos determinar si el Tribunal está limitando los derechos a lo largo del tiempo si -a diferencia de muchos tribunales supremos o constitucionales nacionales- nunca ha revocado expresamente una sentencia anterior en un sentido que favorezca al Gobierno? Para ello, analizamos sistemáticamente las opiniones minoritarias (separadas) de la Gran Sala del TEDH, el órgano plenario de diecisiete miembros que aborda las cuestiones más importantes en materia de derechos humanos y resuelve las incoherencias de la jurisprudencia anterior (Mowbray, 2007, p. 510). ${ }^{10}$ Detectamos opiniones minoritarias en las que se afirma que la Gran Sala ha revocado sentencias anteriores o doctrina consolidada para favorecer al Gobierno demandado, las cuales son llamadas "disidencias por regresión”. La gran mayoría de estas opiniones minoritarias (85\%) se denominan "disidencias", el resto son opiniones concurrentes que están de acuerdo con el resultado del caso, pero que, sin embargo, acusan a la mayoría de revocar la jurisprudencia o la doctrina anterior. Para facilitar la lec-

8 Donde se concluye que, por término medio, una sentencia del TEDH es responsable de que otros cinco países adopten políticas favorables a los derechos de las personas LGBT en los cinco años inmediatamente posteriores a la sentencia y de que otros ocho países lo hagan durante una década

9 Véase, por ejemplo, Madsen et al. (2018).

10 Las Cámaras del TEDH tienen "formalmente prohibido revocar la sentencia". Véase Schabas (2015, p. 711). Deben renunciar a la competencia a favor de la Gran Sala "cuando la resolución de una cuestión [...] pueda tener un resultado incompatible con una sentencia dictada anteriormente por el Tribunal". Véase CEDH, nota 2 supra, art. 30. 
tura, denominamos a todas las opiniones minoritarias que contienen este tipo de afirmaciones como "disidencias por regresión".

Reconocemos que los jueces del TEDH pueden discrepar razonablemente sobre cómo interpretar decisiones y doctrinas jurídicas anteriores. Lo que la minoría percibe como una anulación tácita de un precedente protector de los derechos, la mayoría puede considerarlo como una aclaración de la jurisprudencia del Tribunal o una adaptación a hechos o circunstancias diferentes. También reconocemos que los juristas que escriben opiniones disidentes pueden tener razones normativas y estratégicas para acusar al TEDH de revocar una sentencia. Por ejemplo, pueden hacerlo para agudizar la mordacidad retórica de su crítica, acentuar sus implicaciones políticas o propiciar nuevos casos de futuros litigantes.

Sin embargo, en el caso de un tribunal en el que se prohíbe la derogación expresa de una sentencia anterior en una dirección restrictiva de los derechos, la mayoría siempre justificará una decisión que logre ese resultado, de hecho, si no de forma nominal, por referencia a las diferentes circunstancias de un caso posterior. Incluso si los jueces disidentes tienen diferentes motivaciones para acusar a la mayoría de anulación tácita, un aumento generalizado de disidencias a lo largo del tiempo proporciona pruebas sugestivas de un grupo de actores especialmente bien informados de que el TEDH está, de hecho, retrocediendo en materia de derechos humanos en Europa, aun si no lo está haciendo abiertamente.

Nuestro conjunto de datos comprende la totalidad de las casi 400 sentencias de la Gran Sala desde 1999 (tras la entrada en vigor del Protocolo No 11) hasta 2018. Durante este período de 20 años, el 83\% de las sentencias incluían al menos una (y a menudo más de una) opinión separada, normalmente una disidencia o una concurrencia total o parcial. Con la ayuda de dos asistentes para realizar la búsqueda, codificamos todas estas opiniones formulando tres preguntas: (i) si la opinión era más o menos favorable al Gobierno que la sentencia mayoritaria; (ii) si la opinión afirmaba que la mayoría había anulado explícita o tácitamente una sentencia anterior del TEDH o había interpretado erróneamente o ignorado la jurisprudencia anterior; y (iii) si la opinión afirmaba que la mayoría aplicaba de forma incoherente principios jurídicos clave, como el margen de apreciación, el instrumento vivo o las doctrinas del consenso europeo.

Encontramos que las disidencias por regresión están en aumento, tanto de forma absoluta como proporcional. Por ejemplo, entre 2012 y 2018, 56 senten- 
cias de la Gran Sala (40\%) fueron acompañadas por una o varias disidencias de reversión. Por el contrario, en el período 1999-2005, esto ocurría solo en el $24 \%$ de las sentencias de la Gran Sala. Ofrecemos una serie de ejemplos cualitativos para ilustrar los argumentos de estas opiniones minoritarias, incluidas las afirmaciones de que la anulación tácita refleja un abandono más amplio del papel histórico del TEDH.

También proporcionamos información sobre los jueces, los países y las cuestiones jurídicas de fondo que se asocian con mayor frecuencia a las disidencias. Consideramos la posibilidad de que los casos de la Gran Sala se hayan vuelto más difíciles o controvertidos con el paso del tiempo y, por lo tanto, sean más propensos a generar disidencias por regresión. Encontramos pruebas -incluso después de controlar estas características de los casos- de que las disidencias por regresión se han vuelto significativamente más probables en el período posterior a Brighton.

El presente artículo se desarrolla de la siguiente manera: en el apartado 2 se describen los métodos dinámicos de interpretación de tratados del TEDH y las opiniones de los jueces y los académicos sobre si el Tribunal puede utilizar estos métodos para contraer derechos, así como para ampliarlos. También se examinan los estudios empíricos existentes sobre cómo responde el TEDH a las presiones de los Estados y la literatura sobre las disidencias judiciales. El apartado 3 explica nuestro diseño de investigación, la recopilación de datos, las expectativas teóricas y los procedimientos de codificación, en tanto que el 4 expone nuestro análisis y resultados. El apartado 5 concluye y considera las implicaciones teóricas y normativas más amplias.

\section{La expansión (¿y contracción?) de los derechos humanos en Europa \\ 2.1. La doctrina del instrumento vivo y la ampliación de derechos}

El Convenio Europeo de Derechos Humanos se adoptó en 1950, pero no fue hasta finales de la década de 1970 cuando el TEDH se enfrentó por primera vez a una práctica -los castigos corporales judiciales a los menores- que en su momento se consideraba inofensiva, pero que se había ido abandonando gradualmente. Al considerar que dicho castigo era degradante, el Tribunal declaró que "el Convenio es un instrumento vivo que debe ser interpretado considerando las condiciones actuales". ${ }^{11}$

11 TEDH, Tyrer c/Reino Unido, Appl. N 5856/72, sentencia de 25 de abril de 1978, párrafo 31. Todas las decisiones del TEDH están disponibles en: http://hudoc.echr.coe.int/. 
Durante las cuatro décadas siguientes, la doctrina del instrumento vivo "se extendió por toda la jurisprudencia de Estrasburgo", permitiéndole al Tribunal "adaptar, con el tiempo, el texto del Convenio a la evolución jurídica, social, ética o científica". ${ }^{12}$ Cuando el TEDH detecta un consenso europeo -o, al menos, una convergencia significativa- en las legislaciones y prácticas nacionales de los Estados miembros en favor de una protección más amplia de un determinado derecho o libertad, es más probable que el Tribunal concluya que un Estado que no ha seguido el ritmo de estas tendencias ha violado el Convenio. ${ }^{13}$

El TEDH aplica este enfoque progresivo incluso cuando ello requiere revocar sentencias anteriores. Aunque reconoce que "la seguridad jurídica, la previsibilidad y la igualdad ante la ley" pesan en contra de "apartarse, sin una buena razón, de los precedentes establecidos en casos anteriores”, también ha sostenido que no "mantener un enfoque dinámico y evolutivo supondría el riesgo de convertirlo en un obstáculo para la reforma o la mejora. ${ }^{14}$

Son numerosos y variados los ejemplos en los que el TEDH ha anulado explícitamente sus propias decisiones anteriores y las de la Comisión Europea de Derechos Humanos (Mowbray, 2009). ${ }^{15}$ Entre ellos se encuentran las sentencias que reconocen los derechos de los objetores de conciencia a negarse a realizar el servicio militar, ${ }^{16}$ de los sindicatos a negociar colectivamente con los empleadores ${ }^{17}$ de los hombres homosexuales a impugnar las leyes que penalizan la actividad homosexual privada ${ }^{18} \mathrm{y}$ de las personas transgénero a contraer matrimonio y a obtener los documentos de identidad adecuados. ${ }^{19}$ El Tribunal también ha revocado sentencias relacionadas con cuestiones de procedimien-

12 TEDH, Magyar Helsinki Bizottság c/Hungary, Appl. N 18030/11, sentencia de la Gran Sala de 11 de agosto de 2016, párrafo 3 (Sicilianos y Raimondi JJ., concurrentes).

13 Véanse, por ejemplo, Dzehtsiarou (2015); Helfer (1993).

14 TEDH, Vilho Eskelinen c/Finlandia, Appl. N 63235/00, sentencia de la Gran Sala de 19 de abril de 2007, párrafo 56.

15 Antes del Protocolo $\mathrm{N}^{\circ}$ 11, la Comisión Europea revisaba las solicitudes y emitía decisiones no vinculantes sobre si el Estado demandado había violado el Convenio. La Comisión o el Estado demandado (pero no el demandante) podían apelar estas decisiones ante el TEDH.

16 TEDH, Bayatyan c/Armenia, Appl. N²3459/03, sentencia de la Gran Sala de 7 de julio de 2011 (anulando la jurisprudencia de la Comisión Europea las décadas de 1970 y 1980).

17 TEDH, Demir y Baykara c/Turquía, Appl. N 34503/97, sentencia de la Gran Sala de 11 de diciembre de 2008 (anulando una sentencia del TEDH de mediados la década de 1970).

18 TEDH, Dudgeon c/Reino Unido, Appl. N 7525/76, sentencia del 22 de octubre de 1981 (revocando la jurisprudencia de la Comisión Europea de las décadas de 1950 y 1960).

19 TEDH, Goodwin c/Reino Unido, Appl. N²8957/95, sentencia de la Gran Sala de 11 de julio de 2002 (anulando múltiples sentencias del TEDH desde la década de 1970 hasta la de 1990). 
to, revocando aquellas que rechazaban la ampliación del derecho a un juicio justo a los procedimientos de requerimiento, ${ }^{20}$ negándose a considerar las violaciones del derecho a un recurso interno efectivo si el Estado violaba otras disposiciones del Convenio ${ }^{21}$ y concluyendo que las medidas cautelares no son jurídicamente vinculantes. ${ }^{22}$ Incluso cuando el TEDH se niega a encontrar una violación del Convenio, a menudo señala que está abierto a volver a examinar la cuestión en el futuro. ${ }^{23}$

\section{2. ¿Puede el TEDH retrotraer los derechos?}

El TEDH no ha dudado en anular explícitamente casos anteriores para ampliar los derechos y las libertades, a menudo haciendo referencia explícita a la evolución legislativa, judicial y social en Europa. Pero ¿qué ocurre si estas tendencias se mueven en una dirección más restrictiva de los derechos?

Existen numerosas pruebas correlativas de que los altos tribunales nacionales responden a los cambios en la opinión pública y al "ambiente político". Los estudios sobre el Tribunal Supremo de Estados Unidos, por ejemplo, revelan que cuando la opinión pública y las políticas -incluidas las relacionadas con las libertades civiles y los derechos de los acusados de delitos- se vuelven más liberales (o conservadoras), las sentencias del Tribunal también tienden a ser más liberales (o conservadoras). ${ }^{24}$ Varios mecanismos pueden explicar esta correlación: (i) los políticos pueden nombrar a jueces más liberales (o más conserva-

20 TEDH, Micallef c/Malta, Appl. N 17056/06, sentencia de la Gran Sala de 15 de octubre de 2009, párrafos 75 y 81 (anulando numerosas sentencias del TEDH de finales de la década de 1990 y de la década de 2000).

21 TEDH, Kudla v. Polonia, App. №30210/96, sentencia de la Gran Sala de 26 de octubre de 2000, párrafos 147-149 (anulando sentencias de principios de la década de 1990 hasta el año 2000 en relación con el derecho a un recurso nacional efectivo).

22 TEDH, Mamatkulov y Askarov c/Turquía, App. № 46827/99 y 46951/99, sentencia de la Gran Sala de 4 de febrero de 2005 (que anula las sentencias del TEDH de principios de la década de 1990 y principios de la de 2000).

23 Véanse, por ejemplo, TEDH, S.H. y otros c/Austria, Appl. N 57813/00, sentencia de la Gran Sala de 3 de noviembre de 2011, párrafo 118 (en el que se afirma que las restricciones a la procreación médicamente asistida es un ámbito "en el que el derecho parece estar en continua evolución y que está sujeto a un desarrollo particularmente dinámico de la ciencia y el derecho [y que, por lo tanto,] debe mantenerse en revisión"); TEDH, Naït-Liman c/Suiza, Appl. N 51357/07, sentencia de la Gran Sala de 15 de marzo de 2018, párrafo 220 (en el que se subraya "el carácter dinámico" de la jurisdicción universal sobre las violaciones de los derechos humanos en los casos civiles, afirmando que "el Tribunal no excluye la posibilidad de que se produzcan evoluciones en el futuro" e invitando a los Estados "a tener en cuenta en sus ordenamientos jurídicos cualquier evolución [pertinente]").

24 Véanse, por ejemplo, Mishler y Sheehan (1993); Friedman (2009). 
dores) de acuerdo con las preferencias políticas del entorno; (ii) a los jueces les puede preocupar que el Tribunal pierda legitimidad si sus decisiones no están en sintonía con la opinión pública; o (iii) los acontecimientos que conforman el estado de ánimo de la opinión pública, como los atentados terroristas u otras amenazas, también pueden afectar los puntos de vista y las opciones interpretativas de los jueces. ${ }^{25}$

En lo que respecta a los tribunales internacionales, hay pruebas fehacientes de que el Tribunal de Justicia de la Unión Europea (TJUE) responde a las señales enviadas por los Estados miembros que expresan su preferencia por una mayor o menor integración europea (Carrubba et al., 2008; Larsson y Naurin, 2016). Del mismo modo, las observaciones de terceros Estados están fuertemente correlacionadas con la dirección y el contenido de las sentencias de los órganos de resolución de conflictos de la Organización Mundial del Comercio (Busch y Reinhardt, 2006). No hay estudios equivalentes sobre el TEDH en los que las observaciones de otros Estados miembros sean menos comunes (Bürli, 2017, p. 9). Sin embargo, hay pruebas de que los Gobiernos más euroescépticos tienden a designar candidatos que favorecen la autolimitación judicial en comparación con los candidatos de los Gobiernos menos euroescépticos (Voeten, 2007).

Aunque es bastante común que los tribunales respondan a su entorno político y social, no conocemos otro sistema jurídico en el que fuertes argumentos normativos limiten la dirección de la respuesta de un tribunal. El auge del terrorismo transnacional suscitó por primera vez un debate sobre si el TEDH puede o debe considerar las tendencias regresivas de la legislación y la política nacionales. Como ha señalado Jeffrey Brauch (2005):

\begin{abstract}
A medida que el mundo se hace más pequeño y la tecnología avanza, el terrorismo representa una amenaza mayor y más inminente. Las naciones están respondiendo con más fuerza y agresividad a esa amenaza. Al hacerlo, el "consenso" del futuro sobre lo que se necesita para luchar contra el terrorismo internacional puede abarcar medidas más estrictas y más violaciones de la intimidad de las personas, quizá las mismas medidas e infracciones que hoy consideramos violaciones de los derechos humanos. Pero bajo un estándar de consenso pueden no constituir violaciones en el futuro. (p. 146)
\end{abstract}

La ampliación de la Convención a Europa del Este en la década de 1990 suscitó preocupaciones similares. La diversidad de las tradiciones jurídicas, so-

25 Véase Epstein y Martin (2010). 
ciales y políticas de estos países llevó a estudiosos como Paolo Carozza (1998) a afirmar que

no solo deberíamos esperar en la práctica, sino estar de acuerdo en principio que la dilución del consenso ocasionada por la integración de un círculo cada vez más amplio de Estados miembros se traduzca en una disminución de las normas ya establecidas. (p. 1231)

Los defensores de una aplicación bidireccional de las doctrinas del instrumento vivo y del consenso europeo presentan una afirmación normativa más general: "No hay ninguna razón de peso para que la protección de los derechos humanos no disminuya si el consenso es el principal determinante de la existencia de un derecho" (Brauch, 2005, p. 146). ${ }^{26}$

Otros estudiosos disienten. Para Alec Stone Sweet, la lógica del "activismo mayoritario" funciona en una única dirección: "Una vez que se ha perdido la autonomía normativa nacional en un ámbito determinado, los Estados nunca la han recuperado. Hasta la fecha, ninguna sentencia del TEDH ha sido anulada" (Stone Sweet y Brunell, 2013, p. 81). Según George Letsas (2013), la interpretación evolutiva "denota un proceso de descubrimiento moral" que requiere "ignorar el consenso e impedir que las preferencias mayoritarias tengan efecto sobre los intereses fundamentales de los individuos" (p. 124). Las tendencias restrictivas de los derechos son irrelevantes para esta "lectura moral" del Convenio, lo que le impide al Tribunal realizar interpretaciones regresivas de los derechos (p. 132).

Los jueces del TEDH están igualmente divididos. El punto de vista del "trinquete unidireccional” fue defendido con más fuerza por el juez Casadevall en una opinión disidente en el caso Gorou c/Grecia:

Una vez que [el Tribunal] ha decidido ampliar los derechos de los individuos [...] no debe [...] revertir su decisión. Los derechos adquiridos en la causa de los derechos humanos son al menos tan valiosos como los derechos adquiridos en otras ramas del derecho y, por tanto, debe prevalecer el principio de no regresión. ${ }^{27}$

26 Véase también O’Mahony y Dzehtsiarou (2013), quienes afirman que "no hay nada en principio que impida que el TEDH se retracte de decisiones anteriores y restrinja el alcance aceptado de una determinada garantía" (p. 339).

27 TEDH, Gorou c/Grecia (N²), Appl. N 12686/03, sentencia de la Gran Sala de 20 de marzo de 2009. 
El expresidente del TEDH, el juez suizo Luzius Wildhaber, no está de acuerdo. Criticando la opinión del juez Casadevall, escribe:

La idea de que se deba aplicar un "trinquete" al proceso interpretativo [...] no tiene ni una base convencional ni de derecho consuetudinario ni una justificación razonada en la jurisprudencia del Tribunal o en la práctica y las reacciones de los Estados a esta jurisprudencia. Las sociedades democráticas pueden, y a veces deben, cambiar sus valores y leyes, especialmente cuando se enfrentan a un terrorismo generalizado y vicioso que pone en peligro la vida. (Wildhaber, 2016, p. 296)

El debate entre jueces y académicos no se ha reflejado (todavía) en la jurisprudencia del Tribunal. En particular, nuestro examen de todas las sentencias de la Gran Sala revela que el TEDH nunca ha revocado expresamente una sentencia anterior en un sentido restrictivo de los derechos. Tampoco conocemos ninguna sentencia mayoritaria que cite el instrumento vivo, el consenso europeo u otra doctrina jurídica para justificar la limitación de un derecho que el Tribunal había ampliado previamente. Lo que sí hemos observado son sentencias recientes en las que los jueces autores de las opiniones minoritarias afirman que la Gran Sala ha revocado tácitamente la jurisprudencia o la doctrina anteriores.

Un ejemplo adecuado es Animal Defenders International c/Reino Unido, un caso de 2013 relativo a una prohibición general de la publicidad política de pago. ${ }^{28}$ Aunque una Sala había estimado una impugnación de una prohibición suiza casi idéntica más de una década antes, ${ }^{29}$ la Gran Sala, por una votación de 9 a 8, concluyó que las restricciones del Reino Unido no violaban el derecho a la libertad de expresión. Los jueces disidentes rechazaron el intento de distinguir los dos casos, acusando a la mayoría de "anular, al menos en lo esencial", la sentencia anterior. ${ }^{30}$ También es ilustrativo el caso Khlaifia c/Italia, ${ }^{31}$ de 2016, que interpreta la prohibición de la expulsión colectiva de extranjeros. En un

28 TEDH, Animal Defenders International c/Reino Unido, Appl. № 48876/08, sentencia de la Gran Sala de 22 de abril de 2013.

29 TEDH, VgT Verein gegen Tierfabriken c/Suiza, Appl. № 24699/94, sentencia de 28 de junio de 2001.

30 TEDH, Animal Defenders International c/Reino Unido, párrafos 1 y 9 (Ziemele, Sajó, Kalaydjieva, Vučinić y De Gaetano JJ., en disidencia); véase también ídem en párrafo 12 (Tulkens con Spielmann y Laffranque JJ., en disidencia), caracterizando la sentencia de la mayoría como "incompatible con [...] la jurisprudencia anterior".

31 TEDH, Khlaifia y otros c/Italia, Appl. N 16483/12, sentencia de la Gran Sala de 15 de diciembre de 2016. 
caso anterior contra Italia, la Gran Sala interpretó la prohibición de forma expansiva, "impidiendo que los Estados puedan expulsar a un determinado número de extranjeros sin examinar sus circunstancias personales". ${ }^{32}$ Sin embargo, en la sentencia posterior, sostuvo que la prohibición "no garantiza el derecho a una entrevista individual en todas las circunstancias", ${ }^{33}$ una conclusión que un juez disidente reprochó como "un grave e injustificado retroceso en la protección de los derechos humanos en materia de expulsión". ${ }^{34}$

Estos votos particulares sugieren que el Tribunal, al menos a los ojos de algunos jueces, podría haber comenzado a retroceder en materia de derechos humanos en Europa. Antes de investigar la frecuencia de los votos particulares y si están aumentando, primero revisamos los estudios sobre si la jurisprudencia del TEDH ha cambiado en los últimos años, y luego discutimos el papel de los votos particulares en general y de los votos particulares en específico.

\subsection{Estudios existentes sobre los cambios en la jurisprudencia del TEDH}

Los académicos están empezando a investigar las decisiones del TEDH antes y después de los acontecimientos descritos en la introducción de este artículo, utilizando enfoques cuantitativos y cualitativos. Mikael Madsen (2018) compara todas las sentencias del TEDH entre 2009 y 2015 y encuentra "un aumento estadísticamente significativo del porcentaje de casos que hacen referencia al margen de apreciación o a la subsidiariedad durante todo el período" ( $\mathrm{p}$. 210). A partir de esto, concluye que el TEDH "proporciona más subsidiariedad en general tras la Declaración de Brighton” (p. 221). Janneke Gerards (2018) ofrece una comparación cualitativa del contexto en el que aparecen estas dos doctrinas en los casos resueltos en los períodos 2012-2013 y 2016-2017. Expresa, al contrario que Madsen, que el Tribunal invoca el margen de apreciación principalmente como un "dispositivo retórico vacío" que no "determina el rigor y los estándares de revisión” (Gerards, 2018, pp. 497, 506).

Başak Çali (2018) sostiene que el Tribunal está aplicando cada vez más un enfoque de geometría variable que otorga mayor deferencia a los Estados que aplican la jurisprudencia del TEDH de buena fe, mientras que desarrolla una "jurisprudencia de mala fe" para los Estados que hacen caso omiso de las nor-

32 TEDH, Hirsi Jamaa y otros c/Italia, Appl. N²7765/09, sentencia de la Gran Sala de 23 de febrero de 2012, párrafo 177.

33 TEDH, Khlaifia y otros c/Italia, párrafo 248.

34 Ibídem, párrafos 12 y 16 (Serghides J., parcialmente en disidencia). 
mas de derechos humanos establecidas (p. 242.). Oddný Arnardóttir (2018) identifica una tendencia diferente. Afirma que el Tribunal posterior a Brighton les está dando un mayor margen de apreciación a los tribunales y parlamentos nacionales que siguen determinados procedimientos de toma de decisiones ( $\mathrm{p}$. 223). Sin embargo, al igual que Çali, Arnardóttir (2018) concluye que el actual Tribunal ha redefinido su relación con las autoridades nacionales otorgando más deferencia "en virtud del principio de proporcionalidad a aquellas autoridades nacionales que muestran la debida diligencia de la Convención aplicando la jurisprudencia y las metodologías analíticas del Tribunal en su país” (p. 223). En consonancia con estas afirmaciones, Øyvind Stiansen y Erik Voeten (2020), luego de analizar todas las sentencias del TEDH hasta mediados de 2016, observan que el Tribunal ha encontrado recientemente menos violaciones por parte de las democracias establecidas, mientras que las tasas de violación contra las no democracias y las nuevas democracias se han mantenido estables.

Los estudios anteriores sugieren que los resultados de los casos han cambiado en los últimos años. Sin embargo, esto no nos indica si el TEDH está de hecho haciendo retroceder los derechos humanos. Incluso si, en promedio, los índices de violación han disminuido con el tiempo, esa tendencia podría reflejar simplemente la maduración del Tribunal. Tal vez los tipos de casos de los que se ocupa ahora la Gran Sala sean más complejos o los demandantes estén presionando al TEDH para que sea aún más progresista, lo que conduce a una menor tasa de conclusiones sobre violaciones. Un Tribunal que es menos propenso a respaldar las peticiones de interpretaciones más amplias de los derechos humanos no es lo mismo que un Tribunal que esté reduciendo las interpretaciones anteriores.

\subsection{El papel de los votos particulares}

Las normas que rigen los votos particulares varían mucho entre los tribunales superiores internacionales y nacionales: desde una prohibición total en un extremo hasta tribunales cuyas sentencias incluyen regularmente múltiples votos particulares en el otro (Dunoff y Pollack, 2017; Kelemen, 2018). Las diferencias en el diseño institucional, la cultura judicial y los antecedentes profesionales de los jueces también influyen en la frecuencia de las opiniones minoritarias en los tribunales, que les permiten a los jueces publicar sus opiniones individuales (Bentsen, 2018). La investigación sobre los votos particulares en los tribunales nacionales es mucho más extensa que los estudios similares sobre los tribunales 
internacionales, pero los estudiosos han identificado un conjunto común de ventajas y desventajas asociadas a esta práctica.

Los beneficios de los votos particulares incluyen la mejora de la calidad del razonamiento de un tribunal, la mejora de la independencia judicial, la transparencia y la responsabilidad, la demostración de la deliberación judicial -incluyendo la revelación a las partes de que sus argumentos han sido cuidadosamente considerados- y el suministro de información a otros jueces, futuros litigantes, grupos de cumplimiento y el público sobre los errores del enfoque de la mayoría, las trayectorias futuras alternativas de la ley o la necesidad de legislación o revisiones de tratados (Vitale, 2014). Las desventajas de las opiniones minoritarias incluyen: reducir la seguridad jurídica y la previsibilidad, erosionar la cooperación profesional, dañar la autoridad y la legitimidad de un tribunal al "socavar la credibilidad del argumento de que la decisión alcanzada se basa únicamente en principios jurídicos sólidos" y (especialmente para los tribunales internacionales) aumentar el riesgo de incumplimiento (Naurin y Stiansen, 2020, p. 964). ${ }^{35}$

El TEDH les ha permitido a los jueces presentar votos particulares desde su creación. Las opiniones concurrentes y disidentes son habituales y se han mantenido relativamente estables a lo largo del tiempo. ${ }^{36}$ Entre 1960 y 1997 -justo antes de la entrada en vigor del Protocolo No 11 - el 42\% de las sentencias de las Salas y el 78\% de las sentencias de la Gran Sala incluían uno o más votos particulares (Wildhaber, 1999, pp. 530-531). Los datos que recogimos para los veinte años siguientes muestran solo un modesto aumento de las sentencias de la Gran Sala con opiniones minoritarias (83\%). Un estudio de 2009 proporciona información adicional para evaluar la división jurisprudencial entre los jueces del TEDH:

Aproximadamente el 25\% de las sentencias de Estrasburgo sobre el fondo son unánimes, el 15\% contiene al menos una opinión disidente y el $60 \%$ contiene al menos una opinión concurrente separada. Esto significa que 85 casos de cada 100 son unánimes en cuanto al resultado, incluso si el razonamiento para ese resultado no es el mismo en la mente de todos los jueces. (White y Boussiakou, 2009, p. 53)

35 Véase también Vitale (2014, p. 92), en el que se analiza la relación entre las opiniones en disidencia y el incumplimiento.

36 Véase, por ejemplo, White y Boussiakou (2009, p. 50), en el que se constata que las sentencias no unánimes oscilaron entre el $69,5 \%$ y el $84,5 \%$ entre 1999 y 2004 , inclusive. 
Estas tasas relativamente altas de concurrencias y disidencias en el TEDH no son sorprendentes. Los estudios sobre los tribunales constitucionales y superiores nacionales revelan que los votos particulares son más frecuentes en los tribunales que conocen de casos complejos y políticamente relevantes y en los tribunales cuyos expedientes se centran en los derechos y las libertades individuales. ${ }^{37}$ Otros estudios constatan que "la probabilidad de desacuerdo crece con el tamaño del panel” (Epstein et al., 2013, p. 267). La Gran Sala de 17 miembros combina estas tres características.

La mayoría de los análisis sobre los votos particulares del TEDH se centran en las pautas de votación de los jueces, como por ejemplo si los jueces nacionales disienten más a menudo que sus colegas cuando el Tribunal falla en contra del Estado que los propuso o nombró. ${ }^{38}$ Algunos estudios investigan las correlaciones entre los índices de los votos particulares y la trayectoria profesional de un juez con algunas pruebas que sugieren que los antiguos académicos escriben votos particulares en mayor proporción que los jueces que anteriormente sirvieron en los tribunales nacionales, y que los antiguos diplomáticos tienden a ser más propensos a disentir a favor del Gobierno demandado. ${ }^{39}$

Fuera de estos temas, los estudiosos han prestado poca atención al papel de los votos particulares en el TEDH.

La aplicación del instrumento vivo y de las doctrinas del consenso europeo a menudo genera divisiones entre los jueces del TEDH sobre el alcance y la rapidez de la evolución del Convenio, incluida la posibilidad de anular la jurisprudencia anterior en una dirección progresiva. Sin embargo, los miembros del Tribunal coinciden en que los derechos humanos pueden ampliarse -y de hecho lo hacen- con el paso del tiempo; el desacuerdo estriba en reconocer o no dicha ampliación en un caso concreto. Por el contrario, los disidentes por regresión acusan a la Gran Sala de anular la jurisprudencia en una dirección restrictiva de los derechos, un movimiento jurisprudencial que el TEDH nunca ha respaldado y que sigue siendo muy discutido. Los disidentes por regresión también acusan a la mayoría -a veces, como mostraremos más adelante, con un lenguaje enérgico e incluso apasionado- de disminuir los derechos mediante el sigilo o el subterfugio.

Por lo tanto, esperamos que los jueces no escriban o se sumen a la ligera

37 Véanse, por ejemplo, Bentsen (2018, p. 194); White y Boussiakou (2009, pp. 50-51).

38 Véanse, por ejemplo, Kuijer (1997); Voeten (2008).

39 Véanse Bruinsma (2008, pp. 36-37); White y Boussiakou (2009, p. 571). 
tales disidencias porque, al hacerlo, se corre el riesgo de socavar la cooperación profesional del TEDH y de disminuir su autoridad y legitimidad. Reconocemos, sin embargo, que la frecuencia y el contenido de los votos particulares, así como las inferencias que pueden extraerse de ellos, dependen en parte de la cultura de disidencia de un tribunal, que puede cambiar con el tiempo. ${ }^{40} \mathrm{El}$ siguiente apartado examina los cambios en el entorno político e institucional del Tribunal que pueden afectar la incidencia de las opiniones minoritarias de la Gran Sala.

\section{Expectativas y datos}

\subsection{Expectativas}

Tenemos conjeturas teóricas e históricas sobre cuándo y por qué los jueces del TEDH anuncian sus disidencias. Dividimos las sentencias de la Gran Sala en tres períodos -de 1999 a 2005, de 2006 a 2011 y de 2012 a 2018- que se corresponden con la forma en la que los Estados miembros, tanto individual como colectivamente, han respondido a las sentencias controvertidas y con la trayectoria más amplia de la jurisprudencia del TEDH. ${ }^{41}$

\subsubsection{Primer período: de 1999 a 2005}

El primer período comienza tras la entrada en vigor del Protocolo № 11 a fines de 1998, el cual transformó el TEDH en un órgano judicial supranacional permanente y a tiempo completo que incluía una Gran Sala para resolver los casos más importantes.

El Protocolo entró en funcionamiento luego de una década trascendental para el sistema regional de derechos humanos. Tras el final de la Guerra Fría, el número de Estados miembros aumentó a medida que los países de Europa Central y Oriental se adhirieron al Convenio, el expediente del TEDH comenzó a engrosarse con nuevos casos y un número creciente de países incorporó el Convenio en su legislación nacional. En respuesta a un "zeitgeist geopolítico gene-

40 Véase, por ejemplo, Greenhouse (2001): "Aunque la cultura de la disidencia que ahora prevalece no es una invención de la Corte de Rehnquist, es un desarrollo sorprendentemente reciente que ilumina no solamente el enfoque de este tribunal hacia su trabajo, sino también la relación cambiante de la Corte Suprema moderna con el país y con el concepto de derecho en sí mismo”.

41 Otros académicos han identificado estos períodos como marcas de diferentes épocas en la evolución del TEDH. Véanse Çali (2018, pp. 247-250); Christoffersen y Madsen (2013, pp. 237-240); Madsen (2016, pp. 167-175). 
ral [que] favorecía los derechos humanos y el neoconstitucionalismo” (Madsen, 2016, p. 166), la Gran Sala calificó audazmente a la Convención como un "instrumento constitucional de orden público europeo” y adoptó una visión amplia de su autoridad como tribunal constitucional regional (Helfer, 2008, p. 138). ${ }^{42}$

El TEDH continuó en esta línea hasta mediados de la década de 2000. El número de sentencias emitidas por las Salas y la Gran Sala aumentó considerablemente, pasando de 177 en 1999 a 1105 en 2005 (Madsen, 2016, p. 160, fig. 3). Muchos casos abordaron controversias de derechos humanos de gran repercusión, como la prohibición de los homosexuales en el ejército, las restricciones a la libertad de expresión y los fallos en los procedimientos penales, civiles y de inmigración nacionales. Esperamos que durante este período sean relativamente pocas las acusaciones de que la mayoría estaba revirtiendo tácitamente su jurisprudencia en una dirección más favorable al Gobierno.

\subsubsection{Segundo período: de 2006 a 2011}

El panorama político e institucional del TEDH comenzó a cambiar a mediados de la década de 2000. Los sucesos ocurridos en el Reino Unido y en Rusia fueron la causa de un creciente descontento con el Tribunal. En el Reino Unido, el Gobierno respondió a un importante atentado terrorista en 2005 adoptando una política de deportación de extranjeros que suponían un riesgo para la seguridad nacional. La jurisprudencia del TEDH obstaculizó este esfuerzo, bloqueando las expulsiones a países en los que las personas se enfrentaban a un riesgo previsible de tortura, maltratos o juicios injustos. ${ }^{43}$ Ese mismo año, el Tribunal dictó la controvertida sentencia Hirst № 2, en la que se declaraba improcedente la prohibición del voto de los presos. ${ }^{44}$ La decisión desencadenó una fuerte reacción por parte de las tres ramas del Gobierno del Reino Unido, que arremetió públicamente contra el TEDH por "ampliar indebidamente el alcance de la interpretación de los derechos del Convenio a expensas de las bien cualificadas autoridades nacionales" (Çali, 2018, p. 249).

Al mismo tiempo, el Tribunal dictó varias sentencias de gran repercusión contra Rusia, incluyendo casos de ejecuciones extrajudiciales en Chechenia, la

42 Citando Loizidou c/Turkey, 310 Eur. Ct. H.R. (ser. A) (1995), en 27.

43 TEDH, Othman (Abu Qatada) c/Reino Unido, Appl. N 8139/09, sentencia de 17 de enero de 2012. Véase también Gearty (2005, p. 29).

44 TEDH, Hirst c/Reino Unido (N²), Appl. N 74025/01, sentencia de la Gran Sala de 6 de octubre de 2005. 
extradición de rebeldes chechenos y los disturbios en la región separatista de Moldavia respaldada por Rusia (Helfer, 2008, p. 157; Madsen, 2016, p. 167). "Casi inmediatamente después, surgieron problemas con el acatamiento ruso y el descontento político” (Madsen, 2016, pp. 167-168). El Gobierno respondió bloqueando la entrada en vigor del Protocolo No 14, que pretendía reducir la acumulación de casos pendientes. Rusia mantuvo al Protocolo como rehén hasta 2010, privando al Tribunal de valiosas herramientas para hacer frente a su crisis de expedientes.

En respuesta a esta evolución, se espera que el TEDH se muestre más prudente a la hora de interpretar los derechos y libertades protegidos entre 2006 y 2011. En comparación con el período anterior, esta tendencia debería reflejarse en un aumento de las sentencias de la Gran Sala acompañadas de votos particulares en los que se afirme que la mayoría anuló implícitamente los precedentes o aplicó erróneamente la doctrina para favorecer a los Gobiernos nacionales.

\subsubsection{Tercer período: 2012 a 2018}

El Consejo de Europa ha adoptado numerosas reformas del sistema regional de derechos humanos desde su fundación en 1950. Todas ellas ampliaron los derechos y libertades protegidos o introdujeron cambios procesales o técnicos para incrementar la competencia del TEDH y su capacidad de revisión de las denuncias. Esta pauta ininterrumpida terminó en 2012 con la Conferencia de Alto Nivel sobre el futuro de la convención, organizada por el Reino Unido en Brighton. Un proyecto de declaración que se filtró ofrecía un plan para debilitar los poderes de revisión del Tribunal (Helfer, 2012). La declaración final fue más mesurada, pero siguió siendo crítica con la trayectoria del TEDH. Los Estados miembros no solo criticaron la calidad de los jueces y las sentencias del Tribunal, sino que también acordaron añadir un párrafo al preámbulo del Convenio en el que se hiciera hincapié en la subsidiariedad y en la doctrina del margen de apreciación (Çali, 2018, p. 250). Los académicos han identificado la Declaración de Brighton como el inicio de una nueva fase en la evolución del TEDH, marcada por "una difusión del discurso crítico en toda Europa" que incluye a los poderes políticos del Gobierno, además de los jueces nacionales. En particular, las críticas proceden de las democracias establecidas, que antes se consideraban los principales defensores del Tribunal (Madsen, 2016, p. 174). ${ }^{45}$

45 Véase también Christoffersen y Madsen (2013, p. 238). 
El tercer período también marcó un cambio en el apoyo institucional disponible para que los jueces redactaran las opiniones minoritarias. Anteriormente, los jueces del TEDH apenas contaban con la ayuda de los abogados de la Secretaría para redactar las opiniones separadas. Sin embargo, en 2012, la Facultad de Derecho de Yale (y posteriormente otras facultades de Derecho universitarias) comenzó a enviar a recién graduados para que se desempeñaran como asistentes de varios miembros individuales del Tribunal. ${ }^{46}$ Estos jóvenes abogados mejoraron la capacidad de esos jueces para redactar opiniones separadas.

En consonancia con esta evolución, observamos, a partir de 2012 y en comparación con los dos períodos anteriores, un aumento del número y del porcentaje de sentencias de la Gran Sala acompañadas de una o más opiniones disidentes que critican a la mayoría por anular tácitamente los precedentes progresistas o por apartarse de las doctrinas que favorecen los derechos individuales.

\subsection{Datos}

Examinamos las 397 sentencias de la Gran Sala no interestatales y no duplicadas entre la creación del nuevo Tribunal en 1998 y finales de 2018. ${ }^{47}$ Nos centramos en la Gran Sala por razones tanto prácticas como de fondo. No es posible codificar sistemáticamente las más de 10000 sentencias dictadas por las Salas del TEDH. Además, la función de la Gran Sala es conocer los casos más importantes y conciliar las incoherencias de las sentencias anteriores. Las sentencias de la Gran Sala son también declaraciones autorizadas del derecho jurisprudencial de Estrasburgo y son citadas con frecuencia por las salas (Lupu y Voeten, 2012).

De las 397 sentencias de la Gran Sala, 331 tenían al menos una (aunque a menudo varias) opiniones concurrentes, disidentes y/o separadas. Estas sentencias dieron lugar a un total de 791 opiniones judiciales: 509 disidentes, 263 concurrentes y 19 separadas. Recogimos el texto de estas opiniones y las identidades de los jueces que las redactaron o firmaron en el sitio web del HUDOC.

46 Centro Schell para los Derechos Humanos Internacionales, Robina Foundation Human Rights Fellows, disponible en: https://bit.ly/3i5XGUo (listado de los recién graduados de la Facultad de Derecho de la Universidad de Yale que han sido secretarios del TEDH a partir de 2012).

47 Eliminamos dos casos interestatales (entre Turquía y Chipre) que no encajan en nuestro marco conceptual. También eliminamos quince sentencias contra Italia, Turquía y el Reino Unido que eran duplicadas y tenían opiniones separadas idénticas (aparte del nombre del demandante). En años posteriores, la Secretaría agrupó estos casos duplicados como una única sentencia. La agrupación de estas opiniones en una única sentencia garantiza la coherencia a lo largo del tiempo. 
Les pedimos a dos asistentes de investigación (AI) que respondieran tres preguntas. ${ }^{48}$ En primer lugar: ¿la opinión separada era más favorable al demandante o al Gobierno demandado en comparación con la opinión mayoritaria? Por ejemplo, les dimos instrucciones a los AI para que codificaran la opinión como más favorable al demandante si la mayoría no encontraba una violación o no declaraba la solicitud admisible, pero un disidente argumentaba que la mayoría debería haber encontrado una violación o que la solicitud debería haber sido declarada admisible. Les hemos solicitado que codifiquen del mismo modo las opiniones concurrentes o separadas que coincidan con el Tribunal en el resultado de un caso, pero que, no obstante, consideren la demanda más favorable al demandante que la mayoría.

En segundo lugar, les preguntamos a los AI si la opinión separada afirma que la mayoría anula la jurisprudencia anterior de una de estas tres maneras: (i) anulando explícitamente sentencias anteriores (ya sea en una dirección progresista o conservadora); (ii) anulando implícita o tácitamente la jurisprudencia anterior; o (iii) interpretando la jurisprudencia anterior de forma demasiado estricta o demasiado amplia, ignorando la jurisprudencia anterior o no aplicándola. ${ }^{49}$

En tercer lugar, les solicitamos a los AI que codificaran si una opinión separada: (i) discrepa de la mayoría sobre la aplicación de una o más doctrinas legales clave y, además, (ii) afirma que la doctrina se había aplicado de forma más amplia o restringida en la jurisprudencia anterior. Estas doctrinas jurídicas clave incluían el margen de apreciación, la doctrina del "instrumento vivo", el análisis del "consenso europeo", la doctrina de la "eficacia" y el principio "in dubio pro persona" o "pro homine".

La Tabla 1 resume nuestra codificación. Identificamos 249 votos particulares en los que se alegaba que la mayoría había actuado de forma inconsistente

48 En un principio, se les pidió a dos AI que codificaran una muestra aleatoria de 33 juicios que contenían 88 opiniones distintas, que se evaluaron y utilizaron para ajustar el libro de códigos y para instruir a los AI. Uno de los evaluadores codificó todas las opiniones, mientras que el otro codificó una submuestra aleatoria de dos tercios de las opiniones.

49 La fiabilidad entre codificadores sobre si la opinión favorecía al Gobierno o al demandante fue excelente: asignaron la misma puntuación en el 97\% de las opiniones. También coincidieron en el $90 \%$ de las ocasiones en las que la opinión argumentaba que se basaba en una jurisprudencia anterior erróneamente decidida o aplicaba erróneamente la doctrina legal anterior. Encontramos más incongruencias en cuanto a si una opinión distinta acusaba a la mayoría de haberse basado en jurisprudencia pasada ( $77 \%$ de coincidencia). Casi todas las incongruencias procedían de nuestra tercera categoría: casos en los que la mayoría interpreta la jurisprudencia anterior de forma demasiado estricta o demasiado amplia, la ignora o no la aplica. Para todas las categorías, comprobamos y recodificamos todos los casos en los que los codificadores no estaban de acuerdo. 
con el precedente. Solo 8 de ellas acusaban a la mayoría de anular explícitamente la jurisprudencia anterior, pero 46 alegaban que el Tribunal lo había hecho implícitamente. Con mucha más frecuencia (195 opiniones), la minoría afirmaba que la mayoría había interpretado erróneamente la jurisprudencia de una manera que favorecía indebidamente al Gobierno o al demandante.

Tabla 1. Codificación de las opiniones separadas que alegan que la mayoría anuló un precedente según si la opinión favoreció al Gobierno o al demandante

\begin{tabular}{l|c|c|c|c}
\hline & \multicolumn{4}{|c}{ Opinión separada: iprogobierno o prodemandante? } \\
\hline & Prodemandante & Progobierno & No claro & Total \\
\hline Sin anulación & 224 & 182 & 94 & 500 \\
Anulación explíita & 3 & 5 & 0 & 8 \\
$\begin{array}{l}\text { Anulación implíita } \\
\begin{array}{l}\text { Anulación por interpre- } \\
\text { tación de la jurispruden- }\end{array}\end{array}$ & 22 & 24 & 0 & 46 \\
$\begin{array}{l}\text { cia anterior } \\
\text { Interpretación errónea }\end{array}$ & 110 & 84 & 1 & 195 \\
$\begin{array}{l}\text { de la jurisprudencia* } \\
\text { Jurisprudencia anterior } \\
\text { errónea }\end{array}$ & 8 & 9 & 0 & 17 \\
\hline Total & $\mathbf{3 8 1}$ & $\mathbf{3 1 3}$ & $\mathbf{9 7}$ & $\mathbf{7 9 1}$ \\
\hline
\end{tabular}

* Las opiniones separadas pueden encajar en varias categorías; para evitar el doble recuento, informamos solo de la categoría que más claramente indica la anulación.

Además, identificamos 57 opiniones en las que se afirmaba que la mayoría había aplicado principios interpretativos clave -como el instrumento vivo y el margen de apreciación- de forma incoherente con aplicaciones anteriores. ${ }^{50}$ Sin embargo, solo 17 de estas 57 opiniones minoritarias no iban acompañadas de una afirmación de que la mayoría del Tribunal había anulado o malinterpretado implícitamente la jurisprudencia anterior. Para evitar la doble contabilización, la Tabla 1 recoge los casos en los que la minoría solo afirmó una interpretación errónea de la doctrina. Por último, 25 de las 791 opiniones

50 Nuestras reglas para codificar la aplicación errónea de la doctrina exigían que una opinión separada argumentara explícitamente que el Tribunal se desviaba de las aplicaciones anteriores de una doctrina, en lugar de limitarse a afirmar, por ejemplo, que el margen de apreciación se aplicaba de forma demasiado amplia o demasiado restringida en el caso al que se adjuntaba la opinión minoritaria. 
afirmaban que la propia jurisprudencia anterior estaba mal resuelta. Dado que estas opiniones no indican, como tales, que el Tribunal esté retrocediendo en materia de derechos, no las incluimos como "disidencias por regresión".

En total, 381 votos particulares eran más favorables al demandante, 313 lo eran al Gobierno y en 97 casos no estaba claro a qué parte favorecía el voto particular. Mientras que el $23 \%$ de las opiniones concurrentes no podían calificarse como favorables a ninguna de las partes, esto solo ocurría con el 6\% de las opiniones disidentes. ${ }^{51}$ Además, pudimos codificar todas las alegaciones de anulación, excepto tres, en función de si el voto particular favorecía al Gobierno o al demandante.

\section{Análisis y resultados}

Como se explica en la introducción, llamamos "disidencias por regresión" a aquellas opiniones minoritarias que afirman que la Gran Sala ha revocado o interpretado erróneamente la jurisprudencia anterior de forma favorable al Gobierno. Los datos también contienen "disidencias de avance", que afirman que el Tribunal ha revocado o interpretado erróneamente la jurisprudencia anterior de forma favorable al demandante. Como se ha señalado anteriormente, el TEDH revoca regularmente sus sentencias anteriores para ampliar los derechos. Por el contrario, las disidencias por regresión afirman que el Tribunal está llevando a cabo una práctica que nunca ha respaldado y que no reconoce formalmente: revocar tácitamente o malinterpretar las interpretaciones para limitar los derechos y libertades protegidos.

Este apartado examina en primer lugar las tendencias generales de las conclusiones sobre violaciones y de las disidencias por regresión. A continuación, analizamos tendencias más matizadas en los datos, incluyendo los jueces autores de estos votos particulares y el tipo de argumentos que plantean, así como los países y las cuestiones jurídicas más frecuentes en los tres períodos de tiempo.

51 Esta categoría incluye los casos en los que el Tribunal debe equilibrar dos derechos en conflicto. Cuando el TEDH "debe pronunciarse sobre un conflicto entre dos derechos que gozan de igual protección en virtud del CEDH, el Tribunal debe ponderar los intereses en conflicto”. Véase Kaboğlu y Orán c/Turquía, App. No 1759/08, 50766/10 y 50782/10, sentencia de 30 de octubre de 2018, párrafo 69. Un ejemplo común se refiere a las personas cuyas actividades se informan en los medios de comunicación, lo que plantea la cuestión de si se ha logrado un equilibrio justo entre el derecho a la privacidad del individuo y el derecho a la libertad de expresión del periódico. El resultado de este tipo de casos puede "variar en función de si fue presentado en virtud del artículo 8 por la persona que fue objeto del artículo de prensa impugnado o en virtud del artículo 10 por el autor del mismo artículo" (ídem.). 


\subsection{Tendencias generales}

Los estudios empíricos existentes se han centrado principalmente en los resultados de las sentencias del TEDH, es decir, si el Tribunal falla a favor del demandante (declarando a su favor al menos una alegación) o del demandado (declarando que no hay violación de los derechos humanos). La Figura 1 documenta un aumento en el número absoluto y relativo de sentencias de la Gran Sala que no declaran ninguna violación del Convenio. ${ }^{52}$ Entre 1999 y 2005, el Gobierno se impuso en el 29\% de las sentencias de la Gran Sala. Esta cifra aumentó al 33\% entre 2006 y 2011 y al 41\% en el período posterior a Brighton (el descenso en el número de casos en 2006-2011 refleja un menor número de sentencias de la Gran Sala en ese período). ${ }^{53}$

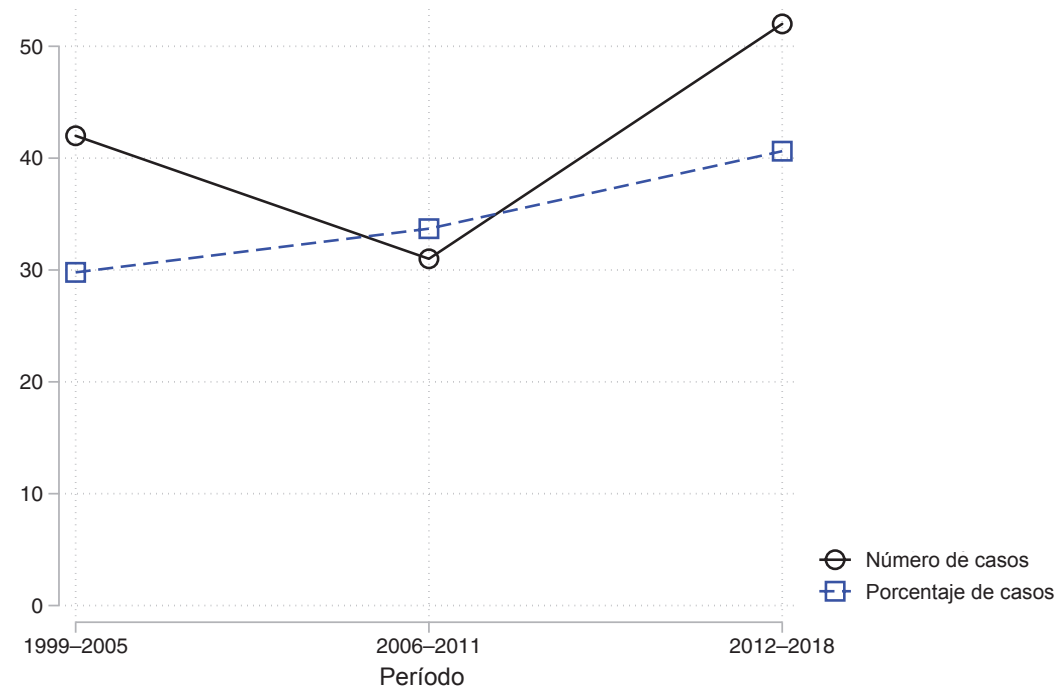

Figura 1. Sentencias de la Gran Sala con conclusiones no violatorias.

52 Un caso declaró la admisibilidad de una solicitud sin llegar a una sentencia sobre el fondo. Lo incluimos con las sentencias favorables a los demandantes. Excluimos 36 sentencias que solo se referían a daños pecuniarios o que anulaban casos porque las partes llegaban a una resolución amistosa. Solo 11 casos se centraron únicamente en cuestiones de admisibilidad (una cuestión que suele tratarse en las decisiones de la Sala). La tendencia básica es sólida al incluir o excluir las decisiones de admisibilidad.

53 Existen patrones similares en las sentencias de las Salas, en las que es menos probable que el Gobierno prevalezca porque muchos casos implican violaciones repetidas. El porcentaje de sentencias por violación disminuyó del 89\% en el período 2006-2011 al 80\% en el período posterior a Brighton. 
La Figura 1 refuerza las conclusiones de estudios anteriores de que el TEDH se ha vuelto más proclive a fallar a favor de los Gobiernos. Sin embargo, esto no indica necesariamente si el Tribunal está retrocediendo en materia de derechos. Los datos de esta figura también son consistentes con un Tribunal que es menos propenso a superar los límites de sus decisiones anteriores, pero que en realidad no da marcha atrás en los precedentes establecidos. El patrón de la figura también podría reflejar la maduración del TEDH. Por ejemplo, es posible que la Gran Sala haya desarrollado previamente jurisprudencia sobre las violaciones más atroces, dejando los casos menos graves que tienen más probabilidades de resultar en sentencias a favor del Gobierno. Por otra parte, los datos podrían subestimar la tendencia favorable al Gobierno. La constatación de una violación no implica necesariamente una victoria para el demandante. Por ejemplo, el Tribunal puede declarar una infracción en una cuestión menor, pero fallar a favor del Estado en las reclamaciones más importantes, o puede fallar a favor del demandante, pero conceder una reparación inadecuada.

La Figura 2 proporciona pruebas directas agregadas de que las disidencias por regresión están aumentando. Además, muestra el porcentaje y el número de sentencias de la Gran Sala con cualquier tipo de voto particular en el que se afirma que la mayoría revocó la jurisprudencia anterior de forma favorable al Gobierno. También muestra claramente que estos votos particulares están aumentando tanto en términos relativos como absolutos. Antes de 2006, el $24 \%$ de las sentencias de la Gran Sala iban acompañadas de un voto particular. Esta cifra aumentó al 30\% entre 2006 y 2011 y al 40\% en el período posterior a $2011 .{ }^{54}$

54 Estos aumentos son estadísticamente significativos al nivel del 95\% según una prueba t. 


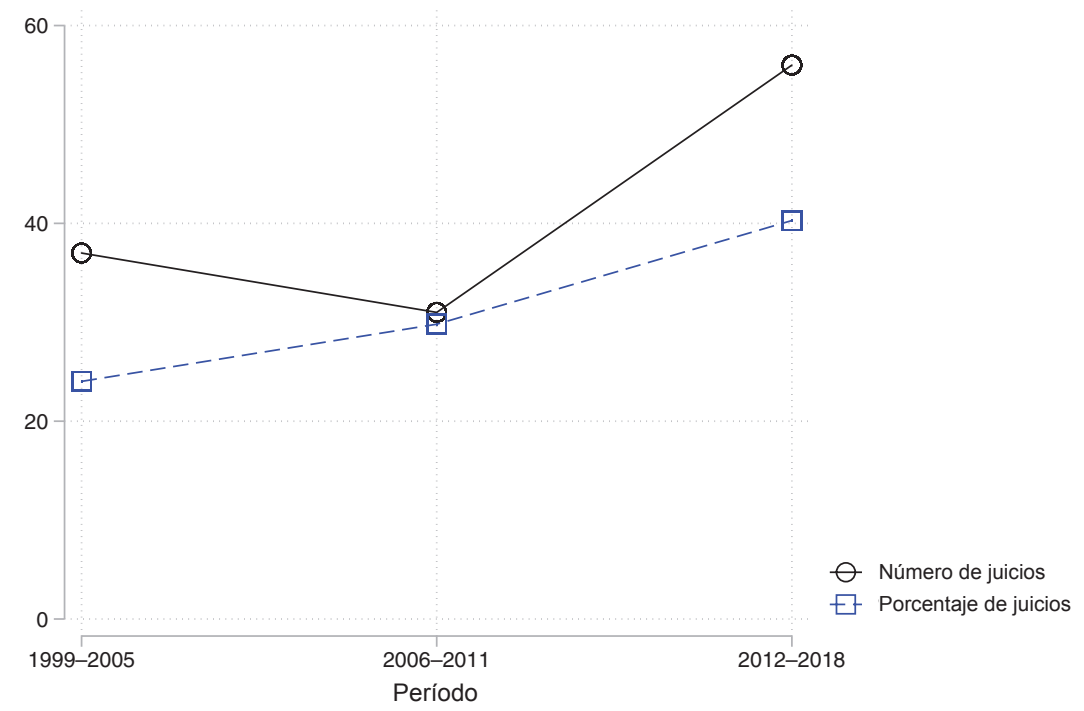

Figura 2. Sentencias con votos particulares que afirman que la Gran Sala revocó la jurisprudencia anterior a favor del Gobierno.

Estos aumentos son consecuentes. Si los jueces hubieran redactado disidencias en la era pos-Brighton al mismo ritmo que antes de 2005, entonces solo 33 (en lugar de 56) sentencias de la Gran Sala habrían ido acompañadas de tal disidencia. Como es lógico, algunos jueces siempre se han quejado de que la Gran Sala es más restringida de lo que la jurisprudencia anterior sugiere que debería ser, sin embargo, tales preocupaciones son mucho más frecuentes en la era posterior a Brighton.

Las pruebas más detalladas de la era posterior a Brighton ayudan a contextualizar esta tendencia. Las 56 opiniones disidentes durante ese período no fueron producto de jueces "lobos solitarios". Solo 19 fueron escritas por un solo juez y 13 fueron firmadas por cinco o más jueces. Por término medio, entre tres y cuatro jueces se sumaron a estas opiniones minoritarias. ${ }^{55}$ Un grupo concreto de jueces es responsable de muchas disidencias por regresión: Tulkens, Rozakis, Sajó, Spielmann y Pinto de Albuquerque escribieron o se unieron a por lo menos 15 de estos votos particulares. Sin embargo, el patrón mostrado en la Figura 1 se mantiene incluso si excluimos los votos particulares que fueron escritos únicamente por estos disidentes seriales.

55 La media es de 3,5 en los períodos posteriores a 2012, de 3,3 en el período 1999-2005 y de 3,1 en el período 2006-2011. 
Resulta interesante que los jueces a veces escriban disidencias por regresión incluso cuando la mayoría falla a favor del demandante. En la era posterior a Brighton, el 36\% de las sentencias de la Gran Sala que declaran al menos una violación del Convenio van acompañadas de este tipo de disidencia (en comparación con el $18 \%$ en los dos períodos anteriores). Normalmente, en estos casos la opinión minoritaria argumenta que el Tribunal debería haber encontrado una violación adicional o debería haber concedido recursos más amplios, como una compensación económica o la reapertura de los procedimientos judiciales. Esta conclusión sugiere que la Figura 1 subestima la reciente tendencia regresiva de la jurisprudencia: hay casos en los que el TEDH constata una violación, pero, sin embargo, es más restrictivo que en el pasado, al menos según la opinión de algunos jueces.

Para obtener un cuadro más completo de la evolución del Tribunal, también examinamos las "disidencias por regresión", es decir, los votos particulares en los que se acusa a la mayoría de revocar la jurisprudencia anterior de forma favorable al demandante. Estas opiniones se adjuntan casi exclusivamente a las sentencias que declaran una o más violaciones del Convenio. Entre 1999 y 2005, el 32\% de las conclusiones sobre violaciones iban acompañadas de un voto particular de este tipo. Esto aumentó al 38\% en el período 2006-2011 y al 53\% en el período 2012-2018. Además, hay indicios de que los votos particulares son cada vez más frecuentes en el conjunto del Tribunal. En la Gran Sala, el $78 \%$, el $73 \%$ y el $90 \%$ de las sentencias en cada uno de los tres períodos, respectivamente, iban acompañadas de al menos un voto particular. Las cifras correspondientes son 37\%, 27\% y $47 \%$ para las sentencias de las Salas más importantes, ${ }^{56}$ y $11 \%$, 9\% y $22 \%$ para todas las sentencias de las Salas en cada período.

El aumento de las disidencias por regresión y de la incidencia de todos los votos particulares es coherente con una conjetura alternativa: que, con el paso del tiempo, el TEDH se está polarizando más ideológicamente con jueces prodemandantes y pro- Gobierno que defienden posiciones opuestas en las opiniones minoritarias. Sin embargo, un análisis más detallado sugiere que hay que ser cautos a la hora de llegar a esta conclusión. En el casi $40 \%$ de los casos de la Gran Sala (41 de 105 sentencias), solamente el juez nacional del Estado

56 El TEDH divide las decisiones en cuatro categorías, siendo el nivel más alto de importancia el de los Informes de Casos o Casos Clave -decisiones seleccionadas para su publicación en el diario oficial del Tribunal-, seguido de los niveles 1, 2 y 3. Véase Tribunal Europeo de Derechos Humanos (s.f.). Los porcentajes citados en el texto corresponden a los informes de casos y a las decisiones de nivel 1. 
demandado firmó el voto particular en el que se acusaba a la mayoría de anular la jurisprudencia a favor del demandante. ${ }^{57} \mathrm{Al}$ igual que todos los jueces del TEDH, los jueces nacionales son independientes y no representan a sus respectivos Gobiernos. Sin embargo, como se ha señalado anteriormente, los estudios han revelado que los jueces nacionales disienten con mucha más frecuencia en los casos en los que se constata una violación del Convenio que los jueces no nacionales. Por lo tanto, es plausible que un voto particular firmado solamente por un juez nacional se considere una prueba débil de que el Tribunal se ha apartado de su jurisprudencia anterior.

Si excluimos los votos particulares "del juez nacional solamente", las disidencias por regresión se presentaron en el 14\%, 16\% y 24\% de todas las sentencias en los tres períodos, respectivamente, y en el 20\%, 27\% y $42 \%$ de las sentencias de violación. Por lo tanto, en aquellas sentencias en las que la Gran Sala considera que existe una violación, hay una tendencia creciente de votos particulares en los que se acusa al Tribunal de haber anulado su jurisprudencia anterior en una dirección progresiva, lo que revela que -al menos para algunos jueces- el TEDH sigue siendo demasiado favorable a la aplicación de algunas cuestiones jurídicas. Los jueces Costa (13), Villiger (10), Wildhaber (9), Turmen (8) y Mahoney (8) se sumaron o redactaron el mayor número de opiniones en las que se acusa al TEDH de haberse desviado de la jurisprudencia anterior hacia una dirección progresista.

\subsection{Ejemplos de disidencias por regresión}

Hasta ahora hemos agrupado los diferentes tipos de disidencias por regresión. Sin embargo, nuestra codificación nos permite extraer información más detallada y tendencias sobre el tipo de afirmaciones realizadas en esas opiniones minoritarias e ilustrarlas con ejemplos concretos.

Los votos particulares en los que se afirma que la mayoría anuló implícita o explícitamente la jurisprudencia anterior a favor del Gobierno han aumenta-

57 Esto incluye 15 sentencias en las que Turquía fue el Estado demandado y cinco en las que lo fue Rusia. Ningún otro Gobierno demandado apareció más de dos veces en esta lista. Como es lógico, no hubo sentencias en las que únicamente el juez nacional argumentara que la mayoría favorecía indebidamente al Estado demandado. Sin embargo, los jueces nacionales, en algunas ocasiones, se unieron e incluso escribieron tales opiniones en nombre de varios jueces. Véase, por ejemplo, TEDH, Moreira Ferreira c/Portugal (N²), Appl. N 19867/12, sentencia de la Gran Sala de 11 de julio de 2017 (Pinto de Albuquerque, Sajó, Tsotsoria, Vehabovi y Kuris, JJ., en disidencia), que se analiza a continuación. 
do significativamente, pasando de dos, en el período 1999-2005, a ocho en el período 2006-2011 y a quince en el período 2012-2018. Estos votos suelen ser bastante contundentes. En el caso Beuze contra Bélgica, por ejemplo, se examinó el derecho de un sospechoso de haber cometido un delito a tener acceso a un abogado mientras estaba bajo custodia policial. Aunque la Gran Sala consideró que se había producido una violación en los hechos presentados, cuatro jueces dedicaron toda una sección de una opinión concurrente conjunto a acusar a la mayoría de "anular" no solo una sentencia anterior, sino toda la línea de jurisprudencia que había generado:

La sentencia Salduz supuso una revolución para los derechos a un juicio justo, al establecer con firmeza que cualquier restricción al derecho de acceso a un abogado debe ser excepcional y susceptible de justificación: "El artículo $6 \S 1$ exige que, por regla general, se facilite el acceso a un abogado desde el primer interrogatorio de un sospechoso por la policía” y que, como se aclaró en Ibrahim y otros, "las restricciones al acceso a la asistencia letrada se permiten solamente en circunstancias excepcionales, deben ser de carácter temporal y deben basarse en una evaluación individual de las circunstancias particulares del caso". La sentencia Beuze representa a este respecto una lamentable contrarrevolución: ha anulado la exigencia "por regla general" -ya repetida en más de un centenar de sentencias ampliamente conocidas como la "jurisprudencia Salduz" - y la ha relativizado drásticamente en detrimento de las garantías procesales. ${ }^{58}$

Algunos votos particulares sostienen que el vuelco tácito del Tribunal en un caso específico significa un retroceso más amplio de su papel histórico, como se ejemplifica en la opinión escrita por los jueces Ziemele, De Gaetano, Laffranque y Keller en Janowiec y otros c/Rusia:

Con esta sentencia, el Tribunal ha perdido la oportunidad de [...] defender la cláusula de los "valores de la Convención" en los principios Šilih. ${ }^{59} \mathrm{Al}$ hacerlo, ha privado a esa cláusula de su efecto humanitario en el caso que nos ocupa y ha debilitado potencialmente su efecto en caso de que se aplique en el futuro. Este enfoque es insostenible si el sistema del Convenio ha de cumplir la función para la que fue concebido: proporcionar un Tribunal que actúe como la "conciencia" de Europa. ${ }^{60}$

58 TEDH, Beuze c/Bélgica, Appl. № 71409/10, sentencia de la Gran Sala de 9 de noviembre de 2018, párrafo 25 (Yudkivska,Vučinić, Turković y Hüseynov, JJ., concurrentes).

59 Los principios Šilih definen el alcance temporal del deber del Estado de investigar las violaciones del derecho a la vida ocurridas en un pasado lejano. Véase Moynihan (2016).

60 TEDH, Janowiec y otros c/Rusia, App. № 55508/07 y 29520/09, sentencia de la Gran Sala de 21 de 
Otro ejemplo interesante es el de Moreira Ferreira c/Portugal (№ 2), que se refiere al rechazo por parte del Tribunal Supremo portugués de una solicitud de reapertura de un procedimiento penal tras una sentencia de la Sala que determinó la violación del artículo 6 (derecho a un juicio justo). La Gran Sala sostuvo, por nueve votos contra ocho, que la decisión del Tribunal Supremo no constituía una violación adicional del artículo 6. En una encarnizada disidencia, los jueces Pinto de Albuquerque, Sajó, Tsotsoria, Vehabović y Kuris argumentaron que el Tribunal estaba retrocediendo en su papel de intérprete autorizado de las normas de derechos humanos en Europa:

[L]a mayoría lo concibe [al TEDH] como un mero órgano consultivo del Tribunal Supremo que, en última instancia, es libre de interpretar las sentencias [del TEDH] como le plazca al Tribunal Supremo, siempre y cuando este exponga algún motivo, cualquier motivo para su interpretación, independientemente del contenido de esos motivos. Aplicando [al TEDH] su propia jurisprudencia [...] habría que concluir que, según la mayoría, [el TEDH] no es un órgano judicial, porque ni siquiera tiene competencia para ordenar una medida individual para reparar una violación del Convenio. ${ }^{61}$

Cabe destacar que esta sentencia también contiene una opinión minoritaria de seis jueces que acusan a la mayoría de hacer exactamente lo contrario: "Anular solapadamente la consolidada jurisprudencia existente" que habría exigido declarar la inadmisibilidad de la solicitud. ${ }^{62}$

Por el contrario, el número de sentencias en las que la minoría afirma que la mayoría ha anulado explícita o implícitamente la jurisprudencia anterior $a$ favor del demandante se ha mantenido prácticamente invariable: de seis, en el período 1999-2005, a trece en el período 2006-2011 y a diez en el período 2012 2018. Algunos de estos votos particulares afirman que el TEDH sigue siendo excesivamente expansivo. Consideremos el caso Del Río Prada c/España, que se refería a las directrices para la imposición de penas a terroristas condenados de la ETA. La disidencia acusa al Tribunal de subterfugio al emitir una sentencia

octubre de 2013, párrafo 34 (Ziemele, De Gaetano, Laffranque y Keller, JJ., parcialmente disidentes).

61 TEDH, Moreira Ferreira c/Portugal (N²), Appl. № 19867/12, sentencia de la Gran Sala de 11 de julio de 2017, párrafo 56 (Pinto de Albuquerque, Sajó, Tsotsoria, Vehabović y Kuris, JJ. en disidencia).

62 Ibíd. párrafo 25 (Raimondi, Nußberger, Gaetano, Keller, Mahoney, Kjølbro y Leary, JJ., en disidencia). Véase también TEDH, Magyar Helsinki Bizottság c/Hungría, Appl. № 18030/11, sentencia de la Gran Sala de 8 de noviembre de 2016, párrafo 30 (Spano y Kjølbro, JJ., en disidencia), afirmando que es "imposible aceptar que la mayoría se limita a 'aclarar' los principios Leander. Por el contrario, que quede claro, hoy la jurisprudencia reiterada del Tribunal [...] ha sido, de hecho, anulada"). 
que en realidad se aparta de la jurisprudencia anterior, pero que "no pretende anular ni apartarse de esa jurisprudencia bien establecida". ${ }^{6}$

Aunque la anulación implícita y explícita ofrece los ejemplos más claros, los votos particulares que alegan la anulación tácita por la aplicación incoherente de la jurisprudencia anterior también acusan a la mayoría de avanzar en una dirección nueva y problemática. Estas afirmaciones suelen ser bastante contundentes. Por ejemplo, como argumentaron los jueces Tulkens, Spielmann y Garlicky en el caso Austin y otros c/Reino Unido:

La posición de la mayoría puede interpretarse en el sentido de que si es necesario imponer una medida coercitiva y restrictiva para un fin legítimo de interés público, la medida no equivale a una privación de libertad. Se trata de una nueva proposición que es eminentemente cuestionable y objetable [...]. ${ }^{64}$

En el caso Regner c/República Checa, un demandante que trabajaba para el Ministerio de Defensa se quejaba de que el procedimiento administrativo para revocar su autorización de seguridad le negaba injustamente el acceso a información clasificada. La opinión disidente del juez Sajó contiene largas secciones en las que se discuten las incoherencias con la jurisprudencia anterior, al igual que la opinión del juez Serghides, que se cita a continuación:

Propongo humildemente que la jurisprudencia no debería haber cambiado de dirección en el presente caso, dando así demasiado rango legal a una restricción absoluta en detrimento de la protección efectiva del derecho de audiencia [...] Hasta ahora hemos sabido que el Convenio prevé algunos derechos absolutos, pero no restricciones absolutas. Una restricción absoluta conduce a la muerte o a la ausencia absoluta de un derecho. ${ }^{65}$

Estos sentimientos no se limitan a las sentencias que no encuentran violaciones. Por ejemplo, en el caso Al-Dulimi y Montana Management Inc. c/Suiza, el Tribunal considera que el Gobierno violó el artículo 6 del Convenio cuando confiscó los bienes del demandante para aplicar una decisión del Comité de Sanciones del Consejo de Seguridad de la ONU. Dos opiniones concurrentes

63 TEDH, Del Río Prada c/España, Appl. N 42750/09, VI Eur. Ct. H.R. 1, 58 sentencia de la Gran Sala de 21 de octubre de 2013 (Mahoney y Vehabovic, JJ., en disidencia).

64 TEDH, Austin y otros c/Reino Unido, Appl. No 39692/09, 40713/09 y 41008/09, sentencia de la Gran Sala de 15 de marzo de 2012, párrafo 3 (Tulkens, Spielmann y Garlicky, JJ., en disidencia).

65 TEDH, Regner c/República Checa, Appl. N 35289/11, sentencia de la Gran Sala de 19 de septiembre de 2017, párrafo 71 (Serghides, J., parcialmente en disidencia). 
alegan que la sentencia de la mayoría es incoherente con sentencias anteriores que abordan posibles conflictos entre el Convenio y las obligaciones de aplicar las resoluciones del Consejo de Seguridad. ${ }^{66}$

Para ser claros, nuestro argumento no es que estas opiniones minoritarias identifiquen correctamente los fallos de la opinión mayoritaria. Tampoco estamos diciendo que la Gran Sala nunca interprete de forma expansiva los derechos y libertades en la era pos-Brighton. Sin embargo, observamos un marcado aumento en las afirmaciones de los jueces de que el TEDH está retrocediendo de su papel tradicional como intérprete progresista de la legislación europea sobre derechos humanos.

\section{3. ¿Geometría variable?}

Como se ha comentado anteriormente, algunos estudios han constatado que el TEDH ha aplicado con mayor frecuencia normas más indulgentes a las democracias establecidas ${ }^{67}$ que a otros tipos de gobiernos (Çali, 2018, p. 242). Algunos miembros del Tribunal también han formulado la misma crítica en opiniones disidentes. Por ejemplo, el juez Pinto de Albuquerque declaró en el caso Hutchinson c/Reino Unido que el "retroceso" de la Gran Sala respecto al caso anterior "no era un hecho aislado", sino el producto de una aplicación sesgada del margen de apreciación, según el cual:

[E]l margen debería ser más amplio para los Estados que se supone que "dan ejemplo a los demás” y más estrecho para los que han de aprender del ejemplo. Evidentemente, esto les deja la puerta abierta de par en par a ciertos Gobiernos para satisfacer su base electoral y proteger sus intereses particulares. En mi humilde opinión, la Convención no se basa en esto. ${ }^{68}$

Nuestros datos proporcionan algunas pruebas que respaldan estas afirmaciones. En el período 1999-2005, Turquía fue el Estado demandado con la mayoría de las sentencias de la Gran Sala acompañadas de disidencias, lo que sugiere que no se le exigieron a Turquía unos niveles de derechos humanos

66 TEDH, Al-Dulimi y Montana Management Inc/c/Suiza, Appl. № 5809/08, sentencia de la Gran Sala de 21 de junio de 2016 (Hajiyev, Albuquerque, Pejchal y Dedov, JJ., concurrente; Keller, J., concurrente).

67 Definido como un país que ha mantenido sistemáticamente una puntuación de Polity de siete o más desde 1988.

68 TEDH, Hutchinson c/Reino Unido, Appl. N 57592/08, sentencia de la Gran Sala de 17 de enero de 2017, párrafo 40 (Pinto de Albuquerque, J., en disidencia). 
suficientemente altos. Por ejemplo, en el caso Sürek c/Turquía (No 1), los jueces Tulkens, Casadevall y Greve argumentaron que el Tribunal se apartó de sus decisiones anteriores, que interpretaban el artículo 10 del CEDH (libertad de expresión) de forma expansiva, al revisar casos que implicaban "declaraciones políticas y críticas a veces virulentas y acerbas contra las acciones de las autoridades turcas". 69

Por el contrario, en el período 2006-2011, los Estados demandados más frecuentes en las sentencias con disidencias por regresión fueron el Reino Unido (siete) y Francia (cinco). En la era posterior a Brighton, el Reino Unido (siete) e Italia (cinco) fueron los más frecuentes en este tipo de casos (y hubo solo una sentencia de este tipo sobre Turquía). En cambio, en el período 1999-2005, apenas el 21\% de las sentencias que implicaban a una democracia establecida iban acompañadas de una disidencia por regresión, frente al 39\% en el período 2006-2011 y el 45\% en el período 2012-2018. No hubo una tendencia similar entre otros tipos de Gobiernos. En resumen, gran parte del aumento de los votos particulares en los que se acusa al Tribunal de dar marcha atrás en la jurisprudencia y las doctrinas jurídicas anteriores procede de sentencias que implican a democracias consolidadas.

\subsection{Cuestiones de fondo}

Los países que han criticado más abiertamente al TEDH están motivados por un conjunto de preocupaciones sustantivas específicas, en particular la jurisprudencia sobre el tratamiento de los detenidos, los inmigrantes y los sospechosos de terrorismo. Estos casos suelen referirse a supuestas violaciones de los derechos a la integridad física (contemplados en los artículos 2, 3 y 5 del $\mathrm{CEDH}$ ) o de los derechos a la intimidad y a la familia (protegidos por el artículo 8 del CEDH).

Las sentencias que plantean estas cuestiones jurídicas son responsables de gran parte del aumento de las disidencias por regresión. En el período posterior a Brighton, 18 de las 56 sentencias de la Gran Sala acusadas de regresión se referían al artículo 8, en comparación con 8 de 37 y 7 de 31 sentencias, respectivamente, en los dos períodos anteriores. Esto no refleja simplemente un aumento en el número total de sentencias del artículo 8. De todas las sentencias de este artículo de la Gran Sala, el 42\% fueron acompañadas de una

69 TEDH, Sürek c/Turquía (N 1), Appl. N²6682/95, sentencia de la Gran Sala de 7 de julio de 1999, párrafo 2 (Tulkens, Casadevall y Greve, JJ., parcialmente en disidencia). 
disidencia por regresión en la era posterior a Brighton (en comparación con el $28 \%$ en el primer período). Las cifras relativas a los derechos de integridad física son similares: 19 disidencias por regresión se referían a los artículos 2, 3 o 5 en el período posterior a Brighton, mientras que el $41 \%$ de todas las sentencias de la Gran Sala relativas a los artículos 2, 3 y 5 fueron acompañadas de una disidencia por regresión en ese período, en comparación con el 35\% y el 28\%, respectivamente, en los períodos anteriores. En conjunto, el porcentaje de sentencias de los artículos 2, 3, 5 y 8 acompañadas de una disidencia por regresión ha aumentado del $25 \%$ al $53 \%$ entre el primer y último período.

No encontramos tendencias similares para otras cuestiones de fondo. Por ejemplo, el número de sentencias de la Gran Sala sobre el artículo 10 (libertad de expresión) que han sido objeto de opiniones disidentes se ha mantenido relativamente constante ( 7,3 y 8 en los tres períodos). El número de casos P1-1 (derechos de propiedad) que atraen tales opiniones tampoco ha aumentado $(6,6$ y 7). En general, el porcentaje de sentencias acompañadas de disidencias por regresión en casos que no invocan los artículos 2, 3, 5 y 8 se ha mantenido constante (35\%) entre el primer y último período de análisis. En resumen, gran parte del aumento de las sentencias que atraen las alegaciones por regresión de derechos se refieren a cuestiones que se han vuelto cada vez más polémicas desde el punto de vista político en las últimas dos décadas en las democracias consolidadas: la integridad física, la intimidad y los derechos de la familia.

\subsection{Análisis de regresión}

Una posible objeción a nuestros resultados es que se deben a cambios en las características observables de los casos. Hemos estimado una serie de modelos de regresión para analizar esta posibilidad. Las unidades de análisis son las sentencias de la Gran Sala. La variable dependiente mide si una sentencia de la Gran Sala va acompañada de una disidencia. El modelo principal 1 (véase la Tabla 2) incluye indicadores para saber si se invocaron los artículos del Convenio mencionados anteriormente, así como un indicador para saber si la sentencia determinó al menos una violación. Como se ha comentado anteriormente, las sentencias que constatan una violación tienen (lógicamente) muchas menos probabilidades de ir acompañadas de una disidencia por regresión, aunque encontramos algunos de estos votos particulares. 
Tabla 2. Análisis de regresión lineal sobre la ocurrencia de disidencias por regresión

\begin{tabular}{|c|c|c|c|}
\hline Variables & Modelo 1 & Modelo 2 & Modelo 3 \\
\hline (1999-2005) & (Categoría de referencia) & & \\
\hline 2006-2011 & $0.06(0.06)$ & $0.07(0.06)$ & $0.05(0.06)$ \\
\hline 2012-2018 & $0.13^{* *}(0.06)$ & $0.15^{* *}(0.06)$ & $0.15^{* *}(0.06)$ \\
\hline Violación & $-0.18^{* * *}(0.05)$ & $-0.18^{* * *}(0.05)$ & $-0.20^{* * *}(0.05)$ \\
\hline Artículo 2 del CEDH & $0.03(0.09)$ & $0.05(0.09)$ & $0.03(0.09)$ \\
\hline Artículo 3 del CEDH & $0.07(0.07)$ & $0.06(0.07)$ & $0.05(0.08)$ \\
\hline Artículo 5 del CEDH & $0.06(0.07)$ & $0.07(0.07)$ & $0.03(0.08)$ \\
\hline Artículo 6 del CEDH & $-0.02(0.05)$ & $-0.01(0.05)$ & $-0.00(0.05)$ \\
\hline Artículo 8 del CEDH & $0.07(0.06)$ & $0.06(0.06)$ & $0.09(0.06)$ \\
\hline Artículo 10 del CEDH & $0.04(0.07)$ & $0.05(0.07)$ & $0.00(0.07)$ \\
\hline P1, Artículo 1 & $-0.02(0.06)$ & $-0.01(0.06)$ & $0.02(0.07)$ \\
\hline Democracia & & $0.06(0.05)$ & $0.05(0.05)$ \\
\hline Prisionero & & & $0.06(0.05)$ \\
\hline Refugiado & & & $-0.08(0.07)$ \\
\hline Informe de caso o caso clave & Categoría de referencia & & \\
\hline Nivel de importancia 1 & & & $-0.14^{* *}(0.06)$ \\
\hline Nivel de importancia 2 & & & $-0.42^{* *}(0.17)$ \\
\hline Nivel de importancia 3 & & & $-0.39^{* *}(0.15)$ \\
\hline Constante & $0.33^{* * *}(0.06)$ & $0.28^{* * *}(0.08)$ & $0.33^{* * *}(0.08)$ \\
\hline Observaciones & 397 & 397 & 366 \\
\hline Coeficiente R2 & 0.06 & 0.07 & 0.11 \\
\hline
\end{tabular}

Errores estándar entre paréntesis.

${ }^{* * *} \mathrm{p}<0.01,{ }^{* *} \mathrm{p}<0.05,{ }^{*} \mathrm{p}<0.1$.

Para evaluar aún más la solidez de los resultados, el modelo 2 incluye una medida para saber si el Estado demandado es una democracia consolidada. Lo definimos como un país que ha recibido una puntuación Polity de siete o superior durante al menos 20 años en $1998 .^{70} \mathrm{El}$ modelo 3 también incluye

70 Esto sigue el enfoque adoptado en Moravcsik (2000). Las democracias consolidadas son: Alemania, Andorra, Austria, Bélgica, Chipre, Dinamarca, España, Finlandia, Francia, Grecia, Irlanda, Is- 
un indicador del nivel de importancia del caso asignado por la Secretaría. La mayoría de las sentencias (78\%) son "casos clave" o "informes de casos". ${ }^{11}$ Esta es la categoría de referencia en el modelo 3. Los coeficientes de los casos de los niveles 1,2 y 3 miden, por tanto, hasta qué punto es menos probable que esas decisiones susciten disidencias. Por último, el modelo 3 incorpora información sobre si el demandante está detenido (preso) o es un refugiado. Esta variable se codificó en función de la aparición de determinados términos (por ejemplo, "detenido" o "asilo") en la descripción de los demandantes. ${ }^{72}$ Sin embargo, esta información solo está disponible para los casos anteriores a 2017.

La Tabla 2 presenta los resultados de un análisis de regresión lineal. (Todos los resultados se mantienen también en una regresión logística, que puede obtenerse de los autores.) La conclusión más importante de la tabla es que la probabilidad de que se produzca una disidencia por regresión ha aumentado entre 13 y 15 puntos porcentuales (según el modelo) en el período posterior a Brighton, en comparación con el período 1999-2005..$^{73}$ Por lo tanto, incluso después de controlar las características de los casos, la probabilidad de una disidencia por regresión ha aumentado significativamente. Esto sugiere que nuestro principal hallazgo descriptivo no se debe a un cambio en las características observables de los tipos de casos que llegan al Tribunal. Aun así, esto no significa que podamos afirmar que hay un efecto causal: podría haber cambios no observables en las características de los casos que no podemos controlar en un análisis estadístico.

Asimismo, esta tabla también revela que, como esperábamos, es mucho más probable que las sentencias por violación vayan acompañadas de una disidencia. Sin embargo, ninguna de las demás características de los casos se correlaciona significativamente con tales disidencias. Nuestro anterior análisis descriptivo demostró que las sentencias relativas a los artículos 2, 3, 5 y 8 del CEDH eran más propensas a atraer disidencias por regresión en el período de 2012 a 2018, pero no en los otros períodos. En un modelo de regresión sobre el período completo de análisis, los coeficientes de regresión sobre estos artículos son positivos, pero no son estadísticamente significativos. ${ }^{74}$ Las únicas excepciones son

landia, Italia, Liechtenstein, Luxemburgo, Malta, Mónaco, Noruega, Países Bajos, Portugal, San Marino, Suecia, Suiza y Reino Unido.

71 Véase la nota 56 supra.

72 Véase Stiansen y Voeten (2020).

73 La diferencia con respecto al período 2006-2011 es de 13 puntos porcentuales.

74 Podrían incluirse efectos de interacción entre los períodos y los artículos para identificar las 
los "informes de casos" o los "casos clave", que tienen más probabilidades de ir acompañados de disidencias por regresión que las sentencias designadas como menos importantes por la Secretaría del Tribunal. Este resultado es coherente con nuestra afirmación de que las disidencias por regresión están asociadas a decisiones que marcan cambios significativos en la jurisprudencia del TEDH.

\section{Conclusión e implicaciones}

Este artículo ha analizado las tendencias generales de la jurisprudencia del TEDH basándose en una revisión y codificación de todos los votos particulares de la Gran Sala entre 1999 y 2018. En los primeros años de estas dos décadas, el TEDH continuó con su larga práctica de interpretar el Convenio como un instrumento vivo que responde a las tendencias de mejora de los derechos en las legislaciones nacionales, incluso anulando las sentencias que no se ajustaban a estos avances. Sin embargo, a partir de mediados de la década de 2000, los Estados miembros, especialmente las democracias establecidas que han sido durante mucho tiempo partidarias incondicionales del TEDH, empezaron a imponer nuevas restricciones a grupos desfavorecidos, especialmente inmigrantes, acusados de delitos y sospechosos de terrorismo. También criticaron públicamente al Tribunal por ampliar demasiado los derechos y las libertades y por no conceder suficiente deferencia a los Gobiernos. Primero de forma vacilante y luego con mayor frecuencia a partir de 2012, la Gran Sala empezó a restringir su interpretación de la Convención, especialmente en casos contra democracias consolidadas.

Lo que el TEDH no ha hecho -al menos no explícitamente- es revocar su jurisprudencia anterior en una dirección restrictiva de los derechos. Tal movimiento representaría una ruptura brusca y controvertida con el instrumento vivo, el consenso europeo y otras doctrinas de expansión de derechos que el Tribunal ha respaldado durante mucho tiempo. En su lugar, la Gran Sala puede conseguir el mismo resultado de forma indirecta, al pretender conciliar sentencias anteriores favorables a los derechos con decisiones posteriores más favorables a los Estados demandados. Sin embargo, para muchos jueces del TEDH, estos esfuerzos son poco convincentes. A modo de protesta por el giro jurisprudencial del Tribunal, estos jueces escriben votos particulares en los que acusan a la mayoría del Tribunal -a veces de forma bastante enérgica

correlaciones cambiantes a lo largo del tiempo. Sin embargo, este tipo de análisis es muy exigente con los datos y daría lugar a estimaciones muy imprecisas. 
y contundente- de anular tácitamente la jurisprudencia anterior o la doctrina establecida en favor de los Gobiernos nacionales.

El aumento de lo que denominamos "disidencias por regresión" revela que algunos miembros del TEDH creen que la Gran Sala está revocando sentencias anteriores en una dirección regresiva. También sugiere que el Tribunal está, de hecho, restringiendo los derechos humanos en Europa. Mostramos que las disidencias por regresión han aumentado tanto en términos absolutos como porcentuales en las últimas dos décadas, siendo el aumento más pronunciado el que se produjo tras la Declaración de Brighton de 2012. También descubrimos que este tipo de disidencias son especialmente comunes en casos contra democracias establecidas y en casos -a menudo presentados por presos, inmigrantes y sospechosos de terrorismo- cuyas protecciones de la Convención han provocado una importante reacción contra el Tribunal.

Existen dos explicaciones posibles para estos resultados. En primer lugar, la Gran Sala puede estar respondiendo a las señales políticas de los Estados miembros de que los jueces de Estrasburgo han sido demasiado agresivos a la hora de interpretar el Convenio, especialmente en los casos que afectan a las democracias de larga data. En segundo lugar, el TEDH puede estar teniendo en cuenta tácitamente el creciente número de Estados miembros que han restringido los derechos de ciertos individuos y grupos minoritarios desfavorecidos, aplicando de hecho las doctrinas del instrumento vivo y del consenso europeo a la inversa.

Sospechamos que ambas tendencias están impulsando el aumento del número de sentencias de la Gran Sala acompañadas de disidencias. Sin embargo, nuestros datos no nos permiten desentrañar estas dos posibles causas ni evaluar su respectiva influencia.

Tampoco excluyen otros factores explicativos, como el nombramiento de jueces que favorecen interpretaciones más restringidas de los derechos humanos. Para desentrañar estos factores, sería necesario, como mínimo, recopilar datos a nivel nacional sobre las tendencias legales progresivas y regresivas en diferentes áreas temáticas, incluyendo aquellas por las que el TEDH ha sido criticado por los Gobiernos y aquellas por las que no. Por ejemplo, los expertos podrían identificar los cambios en los procedimientos nacionales de asilo y examinar si son anteriores o posteriores a los cambios en la jurisprudencia del TEDH.

¿Cuáles son las implicaciones teóricas y normativas más amplias del aumento de las disidencias por regresión? Es bastante habitual que los tribunales constitucionales y superiores nacionales oscilen entre períodos de interpreta- 
ción progresiva y restrictiva, y que algunos derechos se amplíen en una época y se contraigan en otra. Por lo tanto, puede parecer poco llamativo que la Gran Sala retroceda en materia de derechos humanos en Europa, especialmente teniendo en cuenta los importantes cambios recientes en el clima jurídico y político al que se enfrenta el TEDH.

Sin embargo, a diferencia de la mayoría de los tribunales nacionales, el TEDH se ha comprometido desde hace tiempo a ampliar el ámbito y el alcance de los derechos humanos y a respaldar la legitimidad de dichas ampliaciones realizadas por los jueces. Este compromiso es en parte una consecuencia de las normas de competencia y acceso del Tribunal. Dado que los individuos son la fuente de casi todas las reclamaciones, ${ }^{75}$ el TEDH ha desarrollado doctrinas legales que "se centran en los demandantes individuales" e interpretan los derechos de forma expansiva para fomentar la presentación de más casos (Helfer y Slaughter, 1997, pp. 309-312). También opera en paralelo a otro ambicioso proyecto supranacional (la Unión Europea [UE]), con su propio tribunal, famoso por sus propósitos (el TJUE), y con partidarios que defienden una "teoría de la bicicleta” de la integración, según la cual la UE debe expandirse continuamente para evitar la desintegración. ${ }^{76}$ Quizás, lo más importante sea que la visión del TEDH de la Convención como un instrumento vivo ha sido validada (al menos hasta hace poco) por décadas de tendencias jurídicas, políticas y sociales progresistas a nivel nacional y por el compromiso sostenido con el sistema regional de derechos humanos por parte de un número creciente de Estados miembros. De hecho, antes de la Declaración de Brighton de 2012, la totalidad de los numerosos protocolos del Convenio ampliaron la autoridad del TEDH o aumentaron los derechos y libertades que protege (Helfer, 2012).

Estas perspectivas ponen de manifiesto por qué las sentencias de la Gran Sala que hacen retroceder los derechos humanos, incluso tácitamente, son normativas y jurisprudenciales. Lo más evidente es que estas sentencias tienen efectos adversos inmediatos para los miles de individuos vulnerables que buscan una reparación legal en el Tribunal. Pero las sentencias también tienen consecuencias más allá de los litigantes. Cuando el TEDH expone el significado de un determinado derecho o libertad, su interpretación tiene efectos en cadena en los 47 Estados miembros -todos los cuales han incorporado el Convenio a su legislación nacional-y en los poderes judiciales nacionales, en los que

75 Las reclamaciones de grupos, asociaciones y entidades empresariales, así como los casos interestatales, son mucho menos frecuentes.

76 Véase, por ejemplo, Moravcsik (2001, p. 162). 
muchos de sus miembros tienen en cuenta las sentencias del TEDH a la hora de interpretar los derechos o libertades en sus respectivas constituciones. Las sentencias favorables a los Gobiernos que decepcionan a estos actores corren el riesgo de socavar la influencia del Tribunal y su legitimidad.

Al mismo tiempo, el TEDH depende del respaldo político, institucional y financiero de los Estados miembros, especialmente de las democracias establecidas. Cuando ese apoyo disminuye, ya es bastante difícil que el Tribunal haga cumplir a los Estados los compromisos que consintieron expresamente al adherirse al Convenio. Es mucho más peligroso para el TEDH "duplicar" una estrategia de ampliación de derechos y libertades. ${ }^{77}$ Dada la escasez de mecanismos formales a través de los cuales los Estados miembros pueden señalar su apoyo u oposición colectiva a la trayectoria jurisprudencial del TEDH (aparte de las ocasionales conferencias de reforma), no es descabellado que los jueces de Estrasburgo consideren las críticas expresadas por los Gobiernos y tengan en cuenta las tendencias regresivas de las leyes y políticas nacionales.

Equilibrar estas consideraciones contrapuestas es una tarea compleja para cualquier tribunal u órgano de revisión internacional; es aún más difícil para un tribunal de derechos humanos que ha sido alabado como "la joya de la corona del sistema internacional más avanzado del mundo para la protección de las libertades civiles y políticas" (Helfer, 2008, p. 159). Estas cuestiones pueden explicar por qué la Gran Sala ha optado por la anulación tácita y no explícita de las sentencias anteriores (al menos en opinión de algunos de sus miembros) como el enfoque "menos malo" para moverse en un entorno político tenso.

Por un lado, la anulación tácita tiene costes reales. Socava la coherencia y la previsibilidad de la jurisprudencia del TEDH y supone el riesgo de un tratamiento incoherente de los litigantes en situación similar. También genera votos particulares que exponen las fracturas normativas entre los jueces sobre los principios fundamentales. Algunas investigaciones recientes sugieren que las sentencias del TEDH en las que se declara una violación del Convenio y que van acompañadas de una disidencia tienen menos probabilidades de ser aplicadas por el Estado demandado que las sentencias sin dicha disidencia. La lógica en este caso es que las opiniones disidentes "permiten a las partes recalcitrantes argumentar que la decisión del tribunal estaba 'politizada' o no era digna de respeto” (Naurin y Stiansen, 2020, pp. 84-85). No está claro si las disidencias de la marcha atrás tienen efectos similares para los partidarios del Tribunal y 
los grupos de conformidad, disminuyendo su opinión sobre la legitimidad de las sentencias favorables al Gobierno que incluyen esos votos particulares. ${ }^{78}$ Las investigaciones futuras sobre el retroceso en el sistema europeo de derechos humanos podrían investigar si la revocación tácita de las sentencias influye en las estrategias de litigación de los grupos de la sociedad civil que actúan repetidamente ante el TEDH, así como en los esfuerzos de estos grupos para presionar a los Gobiernos con el fin de que nombren a jueces progresistas en el Tribunal. Los académicos también podrían examinar si la revocación tácita anima a los Gobiernos distintos del Estado demandado a reducir la protección de los derechos nacionales, al igual que las sentencias expansivas tienen efectos erga omnes en una dirección progresista (Helfer y Voeten, 2014).

Sin embargo, la revocación tácita también puede tener ventajas. Los estudios sobre los tribunales nacionales e internacionales han revelado que los jueces emiten fallos imprecisos o ambiguos cuando se enfrentan a la incertidumbre política (Staton y Vanberg, 2008). La imprecisión puede "proporcionarles a los funcionarios del Estado una medida de discreción, permitiéndoles la libertad de utilizar los conocimientos locales [...] para alcanzar resultados que los jueces desean, pero que tendrían dificultades para producir sin acceso a mejor información” (Staton y Romero, 2019, p. 477). Las decisiones ambiguas también pueden "atenuar los costes potenciales que los jueces perciben como asociados al incumplimiento" al "dificultar la argumentación de que una orden ha sido realmente incumplida” (p. 478).

En el contexto del TEDH, la ambigüedad puede reducir las presiones de cumplimiento sobre todos los Estados miembros. Por ejemplo, una sentencia de la Gran Sala acompañada de un voto particular que acusa a la mayoría de anular implícitamente una sentencia anterior podría debilitar los efectos erga omnes de ambas sentencias, creando dudas sobre si se aplican a otros países y a circunstancias diferentes y cómo lo hacen. ${ }^{79}$ Los beneficios de la imprecisión también pueden ayudar a explicar por qué observamos un aumento de los vo-

78 Quizás cabe destacar que la lista del blog Observadores de Estrasburgo de las cinco "peores sentencias del TEDH de 2018” incluye dos sentencias de la Gran Sala, ambas con disidencias por regresión. Véanse Poll: Best and Worst ECtHR Judgment of 2018 (2019), que cita al TEDH, Beuze c/ Bélgica, Appl. N 71409/10, sentencia de la Gran Sala de 9 de noviembre de 2018; TEDH, Murtazaliyeva c/Rusia, Appl. N 36658/05, Sentencia de la Gran Sala de 18 de diciembre de 2018. El blog publicó previamente análisis de ambas sentencias de la Gran Sala que criticaban el razonamiento de la mayoría y elogiaban los votos particulares que destacaban las incoherencias con la jurisprudencia anterior del TEDH.

79 El caso de Animal Defenders, comentado anteriormente, que confirmó la prohibición general del Reino Unido sobre la publicidad política pagada a pesar de una sentencia anterior que anulaba una 
tos particulares que acusan a la Gran Sala de revocar tácitamente sentencias o doctrinas anteriores en una dirección favorable a los demandantes: es posible que los jueces del TEDH que forman parte de la mayoría en estos casos se hayan vuelto más circunspectos a la hora de justificar las sentencias progresistas como forma de protegerse de las críticas de los Estados que se oponen a un Tribunal más expansionista.

Una última implicación de nuestras conclusiones se refiere a la reciente oposición nacionalista/populista al sistema multilateral liberal posterior a la Segunda Guerra Mundial, incluidos los tribunales internacionales de derechos humanos y los órganos de revisión. ${ }^{80}$ Las instituciones internacionales que componen este sistema han tendido a ampliar sus competencias con el tiempo. ${ }^{81} \mathrm{Los}$ mecanismos precisos de estas ampliaciones varían, ${ }^{82}$ pero un elemento común que conecta estos diversos ejemplos es que las ampliaciones de autoridad han sido mucho más comunes que las reducciones. Las instituciones internacionales pueden carecer de la flexibilidad y los mecanismos de retroalimentación necesarios para ejecutar correcciones del rumbo que reduzcan su huella legal y política en respuesta a los cambios en el apoyo político y la opinión pública.

El TEDH posterior a Brighton es un ejemplo verosímil de este fenómeno. La anulación tácita que la Gran Sala parece estar utilizando para hacer retroceder los derechos humanos en Europa después de décadas de sentencias dinámicas para mejorarlos -y las controversias que este enfoque ha generado- sugieren la necesidad de reconsiderar si las instituciones internacionales tienen las herramientas adecuadas para reducir -y ampliar- su autoridad a lo largo del tiempo.

\section{Bibliografia}

Arnardóttir, O. M. (2018). The Brighton Aftermath and the Changing Role of the European Court of Human Rights. Journal of International Dispute Settlement, 9(2), 223-239.

Barnett, M. y Finnemore, M. (2004). Rules for the World: International Organizations in Global Politics. Cornell University Press.

prohibición suiza casi idéntica, ofrece un ejemplo adecuado. Véase Animal Defenders International c/ Reino Unido, Appl. N 48876/08, sentencia de la Gran Sala de 22 de abril de 2013.

80 Véanse, por ejemplo, Helfer (2020); Voeten (2020).

81 Véanse, por ejemplo, Helfer (2019); Barnett y Finnemore (2004).

82 Véase, por ejemplo, Bradley y Kelley (2008). 
Bates, E. (15 de diciembre de 2015). The Continued Failure to Implement Hirst v UK. EJIL: Talk! https://bit.ly/3hZ1tmf.

Bentsen, H. L. (2018). Court Leadership, Agenda Transformation, and Judicial Dissent: A European Case of a "Mysterious Demise of Consensual Norms". Journal of Law $\mathcal{E}$ Courts, 6(1), 189.

Bradley, C. y Kelley, J. (2008). The Concept of International Delegation. Law and Contemporary Problems, 76, 1-36.

Brauch, J. A. (2005). The Margin of Appreciation and the Jurisprudence of the European Court of Human Rights: Threat to the Rule of Law. Columbia Journal of European Law, 11, 113.

Bruinsma, J. (2008). The Room at the Top: Separate Opinions in the Grand Chamber of the ECHR (1998- 2006). Ancilla Juris, 32.

Bürli, N. (2017). Third-Party Interventions Before the European Court of Human Rights. Intersentia.

Busch, M. L. y Reinhardt, E. (2006). Three's a Crowd: Third Parties and WTO Dispute Settlement. World Politics, 58(3), 446-477.

Çali, B. (2018). Coping with Crisis: Towards a Variable Geometry in the Jurisprudence the European Court of Human Rights? Wisconsin Journal of International Law, 35(2), 237-276.

Carozza, P. G. (1998). Uses and Misuses of Comparative Law in International Human Rights: Some Reflections on the Jurisprudence of the European Court of Human Rights. Notre Dame Law Review, 73(5), 1217-1238.

Carrubba, C. J., Gabel, M. y Hankla, C. (2008). Judicial Behavior under Political Constraints: Evidence from the European Court of Justice. American Political Science Review, 102(4), 435-452.

Centro Schell para los Derechos Humanos Internacionales. (s.f.). Robina Foundation Human Rights Fellows. https://bit.ly/3i5XGUo.

Ciacchi, A. C. (2017). Political Parties' Programmes: Examples of Governance Against Human Rights? European Journal of Comparative Law and Governance, 4, 105-109.

Comisión Directiva del Consejo de Europa para los Derechos Humanos. (2015). El futuro a largo plazo del sistema del Convenio Europeo de Derechos Humanos.

Christoffersen, J. y Madsen, M. R. (2013). Postscript: Understanding the Past, Present, and Future of the European Court of Human Rights. En Christoffersen, J. y Madsen, M. R. (Eds.), The European Court of Human Rights between Law and Politics (230-249). Oxford.

Dunoff, J. L. y Pollack, M. A. (2017). The Judicial Trilemma. American Journal of International Law, 11(2), 225-276.

Dzehtsiarou, K. (2015). European Consensus and the Legitimacy of the European Court of Human Rights. Cambridge University Press.

Epstein, L., Landes, W. y Posner, R. (2013). The Behavior of Federal Judges: A Theoretical and Empirical Study of Rational Choice. Harvard University Press.

Epstein, L. y Martin, A. D. (2010). Does Public Opinion Influence the Supreme Court? Possibly Yes (But We're Not Sure Why). University of Pennsylvania Journal of Constitutional Law, 13(2), 263.

Friedman, B. (2009). The Will of the People: How Public Opinion Has Influenced the Supreme Court and Shaped the Meaning of the Constitution. Farrar, Straus and Giroux.

Gearty, C. (2005). 11 September 2001, Counter-Terrorism, and the Human Rights Act. Journal of Law and Society, 32(1), 18-33. 
Gerards, J. (2018). Margin of Appreciation and Incrementalism in the Case Law of the European Court of Human Rights. Human Rights Law Review, 18(3), 495-515.

Greenhouse, L. (15 de julio de 2001). Divided They Stand; The High Court and The Triumph of Discord. The New York Times. https://nyti.ms/33Stw1L.

Helfer, L. R. (1993). Consensus, Coherence and the European Convention on Human Rights. Cornell International Law Journal, 26, 133-165.

Helfer, L. R. (2008). Redesigning the European Court of Human Rights: Embeddedness as a Deep Structural Principle of the European Human Rights Regime. European Journal of International Law, 19(1), 125-159.

Helfer, L. R. (2012). The Burdens and Benefits of Brighton. European Society of International Law, 1(1). https://bit.ly/3mHtGS2.

Helfer, L. R. (2019). The ILO at 100: Institutional Innovation in an Era of Populism. AJIL Unbound, 113, 396-401.

Helfer, L. R. (2020). Populism and International Human Rights Institutions: A Survival Guide. En Neuman, G. (Ed.), Human Rights in a Time of Populism: Challenges and Responses. Cambridge University Press.

Helfer, L. R. y Slaughter, A. M. (1997). Toward a Theory of Effective Supranational Adjudication. Yale Law Journal, 107(2), 273-391.

Helfer, L. R. y Voeten, E. (2014). International Courts as Agents of Legal Change: Evidence from LGBT Rights in Europe. International Organization, 68, 77-100.

Kelemen, K. (2018). Judicial Dissent in European Constitutional Courts. Routledge.

Kennedy, R. (22 de febrero de 2019). A "European Race to the Bottom": Human Rights Defenders Criticise Denmark's new immigration bill. Euronews. https://bit.ly/3iXRKOI.

Kuijer, M. (1997). Voting Behavior and National Bias in the European Court of Human Rights and the International Court of Justice. Leiden Journal of International Law, 10(1), 49-67.

Larsson, O. y Naurin, D. (2016). Judicial Independence and Political Uncertainty: How the Risk of Override Affects the Court of Justice of the EU. International Organization, 70(2), $377-408$.

Letsas, G. (2013). The ECHR as a Living Instrument: Its Meaning and Legitimacy. En Føllesdal, A., Peters, B. y Ulfstein, G. (Eds.), Constituting Europe: The European Court of Human Rights in a National, European and Global Context. Cambridge University Press.

Lupu, Y. y Voeten, E. (2012). Precedent in International Courts: A Network Analysis of Case Citations by the European Court of Human Rights. British Journal of Political Science, 42(2), 413-439.

Madsen, M. R. (2016). The Challenging Authority of the European Court of Human Rights: From Cold War Legal Diplomacy to the Brighton Declaration and Backlash. Law and Contemporary Problems, 79, 141-178.

Madsen, M. R. (2018). Rebalancing European Human Rights: Has the Brighton Declaration Engendered a New Deal on Human Rights in Europe? Journal of International Dispute Settlement, 9(2), 199-222.

Madsen, M. R., Cebulak, P. y Wiebusch, M. (2018). Backlash Against International Courts: Explaining the Forms and Patterns of Resistance to International Courts. International Journal of Law in Context, 14(2), 197-220. 
McGoldrick, D. (2011). Religion in the European Public Square and in European Public LifeCrucifixes in the Classroom? Human Rights Law Review, 11(3), 451-502.

Mishler, W. y Sheehan, R. S. (1993). The Supreme Court as a Countermajoritarian Institution? The Impact of Public Opinion on Supreme Court Decisions. American Political Science Review, 87(1), 87-101.

Moravcsik, A. (2000). The Origins of Human Rights Regimes: Democratic Delegation in Postwar Europe. International Organization, 54(2), 217-252.

Moravcsik, A. (2001). Federalism in the European Union: Rhetoric and Reality. En Nicolaidis, K. y Howse, R. (Eds.), The Federal Vision: Legitimacy and Levels of Governance in the United States and the European Union. Oxford Scholarship Online.

Mowbray, A. (2007). An Examination of the Work of the Grand Chamber of the European Court of Human Rights. Public Law, (3), 507-528.

Mowbray, A. (2009). An Examination of the European Court of Human Rights' Approach to Overruling its Previous Case Law. Human Rights Law Review, 9(2), 179-201.

Moynihan, H. (2016). Regulating the Past: The European Court of Human Rights' Approach to the Investigation of Historical Deaths under Article 2 ECHR. British Yearbook of International Law, 86(1), 68-100.

Naurin, D. y Stiansen, Ø. (2020). The Dilemma of Dissent: Split Judicial Decisions and Compliance with Judgments from the International Human Rights Judiciary. Comparative Political Studies, 53(6).

O’Mahony, C. y Dzehtsiarou, K. (2013). Evolutive Interpretation of Rights Provisions: A Comparison of the European Court of Human Rights and the U.S. Supreme Court. Columbia Human Rights Law Review, 44, 309.

Poll: Best and Worst ECtHR Judgment of 2018. (29 de enero de 2019). Strasbourg Observers. https://bit.ly/3kHOjf8.

Schabas, W. A. (2015). The European Convention on Human Rights: A Commentary. Oxford.

Staton, J. K. y Romero, A. (2019). Rational Remedies: The Role of Opinion Clarity in the Inter-American Human Rights System. International Studies Quarterly, 63(3), 477-491.

Staton, J. K. y Vanberg, G. (2008). The Value of Vagueness: Delegation, Defiance, and Judicial Opinions. American Journal of Political Science, 52(3), 504-519.

Stiansen, Ø. y Voeten, E. (2020). Backlash and Judicial Restraint: Evidence from the European Court of Human Rights. International Studies Quarterly, 64(4), 770-784.

Stone Sweet, A. y Brunell, T. L. (2013). Trustee Courts and the Judicialization of International Regimes: The Politics of Majoritarian Activism in the ECHR, the EU, and the WTO. Journal of Law and Courts, 1(1), 61-88.

Tribunal Europeo de Derechos Humanos. (s.f.). HUDOC FAQ: Preguntas frecuentes. https:// bit.ly/3hVFxIN.

Urueña, R. (2018). Double or Nothing? The Inter-American Court of Human Rights in an Increasingly Adverse Context. Wisconsin International Law Journal, 35(2) 398-425.

Vitale, D. (2014). The Value of Dissent in Constitutional Adjudication: A Context-Specific Analysis. Review of Constitional Studies, 19(1), 83-108.

Voeten, E. (2007). The Politics of International Judicial Appointments: Evidence from the European Court of Human Rights. International Organization, 61(4), 669-701. 
Voeten, E. (2008). The Impartiality of International Judges: Evidence from the European Court of Human Rights. American Political Science Review, 102(4), 417-433.

Voeten, E. (2020). Populism and Backlashes against International Courts. Perspectives on Politics, 18(2), 407.

White, R. C. A. y Boussiakou, I. (2009). Separate Opinions in the European Court of Human Rights. Human Rights Law Review, 9(1), 37-60.

Wildhaber, L. (1999). Opinions dissidentes et concordantes de juges individuels à la Cour Européenne des droits de l'homme. En Dupuy, R. J. (Ed.), Droit et justice: Mélanges en l'honneur de Nicolas Valticos (pp. 530-531). Editions A. Pedone.

Wildhaber, L. (2016). The Old Court, the New Court, and Paul Mahoney. Human Rights Law Journal, (36). 
